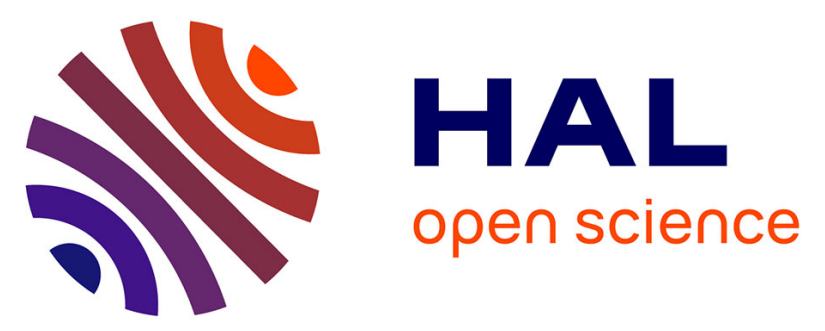

\title{
Transformation of Co-containing birnessite to todorokite: Effects of Co on the transformation and implications for Co mobility
}

Zhongkuan Wu, Caroline L. Peacock, Bruno Lanson, Hui Yin, Lirong Zheng, Zhongjun Chen, Wenfeng Tan, Guohong Qiu, Fan Liu, Xionghan Feng

\section{To cite this version:}

Zhongkuan Wu, Caroline L. Peacock, Bruno Lanson, Hui Yin, Lirong Zheng, et al.. Transformation of Co-containing birnessite to todorokite: Effects of Co on the transformation and implications for Co mobility. Geochimica et Cosmochimica Acta, 2019, 246, pp.21-40. 10.1016/j.gca.2018.11.001 . insu-03022652

\section{HAL Id: insu-03022652 \\ https://hal-insu.archives-ouvertes.fr/insu-03022652}

Submitted on 24 Nov 2020

HAL is a multi-disciplinary open access archive for the deposit and dissemination of scientific research documents, whether they are published or not. The documents may come from teaching and research institutions in France or abroad, or from public or private research centers.
L'archive ouverte pluridisciplinaire HAL, est destinée au dépôt et à la diffusion de documents scientifiques de niveau recherche, publiés ou non, émanant des établissements d'enseignement et de recherche français ou étrangers, des laboratoires publics ou privés. 
1 Transformation of Co-containing birnessite to todorokite:

2 Effects of Co on the transformation and implications for Co mobility

4 Zhongkuan $\mathrm{Wu}^{\mathrm{a}}$, Caroline L. Peacock ${ }^{\mathrm{b}}$, Bruno Lanson ${ }^{\mathrm{c}}$, Hui Yin ${ }^{\mathrm{a}}$, Lirong Zheng ${ }^{\mathrm{d}}$, Zhongjun Chen ${ }^{\mathrm{d}}$, Wenfeng Tan ${ }^{\mathrm{a}}$, Guohong Qiu ${ }^{\mathrm{a}}$, Fan Liu ${ }^{\mathrm{a}, *}$, Xionghan Feng ${ }^{\mathrm{a}, *}$

6

$7 \quad{ }^{\mathrm{a}}$ Key Laboratory of Arable Land Conservation (Middle and Lower Reaches of Yangtse

8 River) Ministry of Agriculture, College of Resources and Environment, Huazhong

9 Agricultural University, Wuhan 430070, China.

$10{ }^{\mathrm{b}}$ School of Earth and Environment, University of Leeds, Leeds LS2 9JT, UK.

$11{ }^{\mathrm{c}}$ University of Grenoble Alpes, CNRS, ISTerre, F-38000 Grenoble, France.

$12{ }^{\mathrm{d}}$ Beijing Synchrotron Radiation Facility, Institute of High Energy Physics, Chinese

13 Academy of Sciences, Beijing 100039, China.

14

15 * Corresponding author:

16 Tel: +86 2787280271

17 E-mail: liufan@mail.hzau.edu.cn (F. Liu), fxh73@mail.hzau.edu.cn (X. Feng). 
Abstract

The mobility and fate of bioessential transition metals, such as $\mathrm{Ni}$ and $\mathrm{Co}$, are strongly controlled by their association with phyllomanganate minerals such as birnessite. These minerals however, can transform to tectomanganates such as todorokite during soil and sediment diagenesis, yet the mobility and fate of most metals during the transformation process remain largely unknown. Here this research investigates the effect of Co on, and the mobility and fate of Co during the transformation of birnessite into tunnel structure minerals. A range of Co-containing birnessite precursors with up to $20 \% \mathrm{Co} /(\mathrm{Co}+\mathrm{Mn})$ molar ratios were synthesised, and subsequently transformed via a mild reflux procedure designed to mimic the diagenesis of these layered precursors into tunnel structures. The layered precursors and reflux products were characterized using a combination of mineralogical and geochemical techniques, including powder X-ray diffraction (XRD), Fourier transform infrared spectroscopy (FTIR), high resolution transmission electron microscopy (HRTEM) and extended X-ray absorption fine structure (EXAFS) spectroscopy. The results show that $\mathrm{Co}(\mathrm{III})$ is structurally incorporated into the layered precursors and reflux products, through the isomorphic substitution of $\mathrm{Mn}(\mathrm{III})$. The structural incorporation of $\mathrm{Co}(\mathrm{III})$ into the layered precursors leads to an overall reduction of Jahn-Teller distorted Mn(III) octahedra in these minerals, a key factor for their transformation to tunnel structures. As a consequence, the presence of such structural $\mathrm{Co}(\mathrm{III})$ disrupts the transformation of birnessite into todorokite, leading to the coexistence of $9.6 \AA$ asbolane-like phyllomanganate and non-ideal $3 \times n$, or $\boldsymbol{a}$-disordered, todorokite-like tectomanganates in the transformation products. Newly formed todorokite exhibits a wide range of $3 \times n$ tunnel dimensions ( $n$ up to 13) and a plate-like morphology. Overall the structural incorporation of non Jahn-Teller distorted cations like $\mathrm{Co}(\mathrm{III})$ into birnessite might help explain the often observed predominance of phyllomanganates over tectomanganates in soils and sediments, and the persistence of phyllomanganates in ferromanganese deposits that can be many 
millions of years old. The results also indicate that $\mathrm{Co}(\mathrm{III})$ initially associated with birnessite is retained in the solid phase during transformation, and thus the mobility of $\mathrm{Co}(\mathrm{III})$ is limited. EXAFS data suggest that Co is mainly located in the octahedral layers of asbolane-like phyllomanganate and at non-edge sites in non-ideal todorokite. Overall the transformation of Co-containing birnessite into non-ideal todorokite and asbolane-like layered structures maintains the strong sequestration of Co by $\mathrm{Mn}$ oxides.

Keywords: layered Mn oxide precursor; birnessite; tunnel structure; todorokite; XRD; EXAFS; nitric acid treatment

\section{6} on $\mathrm{Mn}(\mathrm{III}, \mathrm{IV}) \mathrm{O}_{6}$ octahedra sharing edges and/or corners (Post, 1999). These oxides are ubiquitous, occurring for example in soils, sediments and oceanic ferromanganese crusts and nodules (Taylor et al., 1964; Burns and Burns, 1975, 1977; Chukhrov et al., 1982; Murray et al., 1984; Post, 1999; Vodyanitskii et al., 2004). The coexistence of $\mathrm{Mn}(\mathrm{II} / \mathrm{III} / \mathrm{IV})$ within these oxides, and the related charge deficit that this creates, makes these oxides highly reactive, in particular with respect to the sorption and/or oxidation of transition metals (e.g., Manceau et al. 2002; Tebo et al., 2004; Webb et al., 2005; Peacock and Sherman, 2007a; Peacock, 2009;) and the oxidative degradation of organic contaminants (Tebo et al., 2004; Remucal and Ginder-Vogel, 2014). The reactivity of these oxides is often reinforced by their micro- to nano-crystallinity, which provides them with large specific surface areas (Post, 1999; Lanson et al., 2000, 2002a,b). This strengthens their role as key players in the environmental fate of inorganic and organic nutrients and contaminants (e.g., Villalobos et al., 2005;

2 Lafferty et al., 2010; Grangeon et al., 2012), but in turn often hampers their precise 3 identification (Chukhrov et al., 1987; Post, 1999). 
Two main families of Mn oxides may be differentiated, i.e. phyllomanganates and tectomanganates. Phyllomanganates are 2D minerals whose layers are built of edge-sharing $\mathrm{MnO}_{6}$ octahedra. Layer charge deficit results either from isomorphic Mn(III)-for-Mn(IV) substitutions or from the presence of vacant layer sites. In the first instance, to minimize steric strains arising from the Jahn-Teller distortion of $\mathrm{Mn}(\mathrm{III})$ octahedra, these elementary blocks may be segregated into $\mathrm{Mn}$ (III)-rich rows in which the octahedra are systematically elongated along the same direction (the $\boldsymbol{a}$ axis). The induced cooperative Jahn-Teller effect then leads to an orthogonal layer symmetry $(a>\sqrt{ } 3 b)$, and the layer charge deficit is generally compensated for by the presence of protons, hydrated alkali or alkaline-earth cations (Drits et al., 1997, 2007; Silvester et al., 1997, Lanson et al., 2002a; Webb et al., 2005; Gaillot et al., 2007). In the second instance, the presence of vacant layer sites leads to a hexagonal layer symmetry $(a=\sqrt{3} b)$, where the layer charge deficit is neutralized by interlayer cations such as $\mathrm{H}^{+}, \mathrm{K}^{+}$, and so on (Silvester et al., 1997; Manceau et al., 1997; Lanson et al., 2000; Villalobos et al., 2006; Bodeï et al., 2007; Drits et al., 2007; Peacock and Sherman, 2007b). The vacant layer sites also allow for the sorption of multi-valent cations as inner sphere complexes above/below these sites (triple corner sites: e.g., Post and Appleman, 1988; Manceau et al., 1997, 2002, 2004, 2007; Lanson et al., 2002b; Villalobos et al., 2005; Peacock and Sherman, 2007a, b; Grangeon et al., 2008; Peacock, 2009; Peña et al., 2010). In both orthogonal and hexagonal phyllomanganates, the layer-to-layer distance is $\sim 7.0-7.2 \AA$ (e.g. birnessite, vernadite, chalcophanite; Post and Appleman, 1988; Drits et al., 1997; Silvester et al., 1997; Lanson et al., 2000, 2002a,b). This distance may be increased to $~ 9.4-10.0 \AA$ when interlayer alkali or alkaline-earth cations retain two planes of interlayer $\mathrm{H}_{2} \mathrm{O}$ molecules (i.e. buserite) or when an additional octahedral brucite-like sheet is sandwiched between two Mn octahedral sheets (lithiophorite, asbolane; Chukhrov et al., 1982, 1987; Manceau et al., 1987; Post and Appleman, 1988, 1994; Post, 1999). 
102 octahedra share corners, thus leading to "tunnel" structures. Nomenclature of the

103 natural tunnel oxides relies essentially on the $n \times m$ tunnel size, with ideal pyrolusite, 104 cryptomelane and todorokite having $1 \times 1,2 \times 2$ and $3 \times 3$ tunnel sizes, respectively, and 105 on the nature of the cations present within these tunnels. It is commonly accepted that 106 tectomanganates originate from the transformation of phyllomanganate precursors 107 (Burns and Burns, 1977; Golden et al., 1986; Ching et al., 1999; Feng et al., 1999; 108 Shen et al., 2005; Bodeï et al., 2007; Cui et al., 2008, 2009, 2010; Grangeon et al., 109 2014, 2015; Atkins et al., 2014). For example, todorokite, that exhibits intense 110 diffraction lines at $9.6 \AA$ and $4.8 \AA$ (JCPDS 38-0475), may be prepared by heating 111 Mg-exchanged buserite either in an autoclave or at atmospheric pressure (Golden et 112 al., 1986; Feng et al., 2004). As phyllomanganate precursors often have transition 113 metals sorbed at their surface and/or incorporated within their octahedral layers, the 114 fate of these elements during the phyllomanganate-to-tectomanganate conversion is of 115 special interest for their geochemical cycling (e.g., Siegel and Turner, 1983; Atkins et 116 al., 2014, 2016). Experimental investigations of the mobility and fate of metals during 117 todorokite formation from layered precursors however, show mixed results, with 118 studies reporting both the incorporation of metal ions into the framework of newly 119 formed todorokite (Yin et al., 1994; Ching et al., 1999; Nicolas-Tolentino et al., 1999; 120 Kumagai et al., 2005; Onda et al., 2007) or the loss of metal ions from precursor 121 birnessite with only the surface adsorption of metal ions onto newly formed 122 todorokite (Atkins et al., 2016).

123 In this context, the fate of Co during the transformation of layered precursors is of 124 special interest owing to its high natural affinity for layered Mn oxides. Early 125 observations showed that layered Mn minerals present in Australian soils (birnessite 126 and lithiophorite) contain relatively large amounts of $\mathrm{Co}$ with $\mathrm{Co} /(\mathrm{Co}+\mathrm{Mn})$ molar 127 ratios of $\sim 0.01-0.02$ (Taylor et al., 1964; Taylor, 1968). Similarly, in mining district 128 sediments Co concentration is also positively correlated with the content of Mn oxides 129 (Fuller and Harvey, 2000; Dublet at al., 2017), which can exhibit Co/(Mn+Co) molar 
130 ratios up to 0.34 (asbolane; Manceau et al., 1987). This geochemical Mn-Co 131 association is also recognized in the marine environment, where ferromanganese 132 nodules and crusts composed predominantly of layered Mn oxides are enriched in Co 133 relative to seawater (e.g., Murray, 1975; Burns and Burns, 1977; Murray and Dillard, 134 1979; Saito et al., 2002). Monomineralic Co-containing layered Mn oxides, such as 135 lithiophorite and asbolane, have been identified in soils, lateritic formations and 136 oceanic ferromanganese nodules (Chukhrov et al. 1982, 1987; Ostwald, 1984; Llorca, 137 1987, 1988; Manceau et al. 1987, 1992). Coupled with Co sorption, layered Mn 138 oxides are also able to oxidize $\mathrm{Co}(\mathrm{II})$. The oxidation of $\mathrm{Co}(\mathrm{II})$-to-Co(III) by birnessite 139 was first revealed using X-ray photoelectron spectroscopy (Murray and Dillard, 1979), 140 and later shown to be initiated at the edges of birnessite particles (Simanova and Peña, 141 2015). A combination of polarized extended X-ray absorption fine structure (EXAFS) 142 spectroscopy and X-ray diffraction (XRD) shows that both layer and interlayer Mn(III) 143 can oxidize $\mathrm{Co}$ (II) and lead to Co(III) migration into the octahedral layers (Manceau 144 et al., 1997; Yu et al., 2012). Both Co(II) oxidation and the subsequent migration of $145 \mathrm{Co}(\mathrm{III})$ into the mineral structure appear to be key to the high capacity of layered Mn 146 oxides for Co scavenging (Yin et al., 2014) and their resulting Co-enrichment 147 (Loganathan and Burau, 1973; Davies and Morgan, 1989).As Co(III)O 6 octahedra are 148 not Jahn-Teller distorted, Co-enrichment in birnessite layers may modify layer 149 symmetry from orthogonal to hexagonal (Yin et al., 2015). This enrichment may also 150 impact the ability of Co-containing phyllomanganates to transform into 151 tectomanganates as the abundance of distorted $\mathrm{Mn}$ (III) octahedra within the 152 octahedral layers appears to be a key factor for the formation of tunnel structures 153 (Burns et al., 1985; Bodeï et al., 2007; Cui et al., 2008; Atkins et al., 2014, 2016; 154 Grangeon et al., 2014, 2015; Zhao et al., 2015).

155 To the authors' knowledge only a handful of studies have investigated the 156 transformation of Co-containing layered Mn oxides into tunnel structures (Ching et al., 157 1999; Kumagai et al., 2005; Onda et al., 2007; Song et al., 2010). As expected, Co(II) 
158 is oxidized to $\mathrm{Co}$ (III) in the layered precursors and then indirect observations indicate

159 that a significant proportion of Co in the precursor can be structurally incorporated

160 into the newly formed tunnel structures, by replacing Mn (Ching et al., 1999;

161 Kumagai et al., 2005; Onda et al., 2007; Song et al., 2010). In particular, it is 162 suggested that $\mathrm{Co}(\mathrm{III})$ primarily substitutes for $\mathrm{Mn}(\mathrm{III})$ at the edge sites $(\mathrm{Mn} 2$ and 163 Mn4, Fig. 1) of the $3 \times 3$ tunnel structure (Song et al., 2010). However, the mechanism 164 of Co retention and the extent to which precursor Co is retained in the newly formed 165 products are still unclear, and thus the mobility and fate of Co during the birnessite to 166 todorokite transformation are still unknown.

167 The present study explores the transformation of Co-containing layered Mn oxide 168 precursors into tectomanganates, in order to investigate the effect of Co on, and the 169 fate of Co during the transformation process. A combination of XRD, 170 Fourier-transform infrared (FTIR) spectroscopy, nitric acid treatment and 171 high-resolution transmission electron microscopy (HRTEM) are used to characterize 172 the layered precursors and the transformation products, and determine the effect of Co 173 on their structures. The effect of Co on the transformation process is investigated and 174 the key parameters leading to the formation of layered vs. tunnel structures are 175 determined. These techniques are then combined with X-ray absorption near-edge 176 structure (XANES) and EXAFS spectroscopy to examine the Mn and Co crystal 177 chemistry in the layered precursors and transformation products, in order to better 178 understand the ultimate fate of Co during layered Mn oxide transformation.

\section{EXPERIMENTAL METHODS}

\subsection{Synthesis of layered precursors and transformation products}

A number of different Co-containing layered precursors (birnessite) and 183 transformation products were prepared after Feng et al. (2004) and Song et al. (2010), 184 together with Co-free birnessite and todorokite reference materials. To prepare the layered precursors, $250 \mathrm{~mL}$ of $5.5 \mathrm{M} \mathrm{NaOH}$ solution (refrigerated for $5 \mathrm{~h}$ at $4{ }^{\circ} \mathrm{C}$ ) was 
added quickly to a $200 \mathrm{~mL}$ solution containing $0.5 \mathrm{M}$ (Mn(II)+Co(II)), as $\mathrm{MnCl}_{2}$ and $\mathrm{CoCl}_{2}$, in which the molar ratios of $\mathrm{Co}$ to $(\mathrm{Mn}+\mathrm{Co})$ were $0,0.05,0.10,0.15$ and 0.20 . The mixed solution was then stirred vigorously for $5 \mathrm{~h}$ and aerated with $2 \mathrm{~L} / \mathrm{min}_{2}$. Each precipitate was washed with deionized water until the conductivity was below 2 $\mu \mathrm{S} / \mathrm{cm}$ and half of each precipitate was dried at $60^{\circ} \mathrm{C}$ for 3 days, while the other half was used to prepare todorokite. Layered precursors with molar ratios of $\mathrm{Co} /(\mathrm{Mn}+\mathrm{Co})$ of $0,0.05,0.10,0.15$ and 0.20 are named Bir, CoB5, CoB10, CoB15 and CoB20, respectively, and the Co-containing layered precursors are collectively referred to as CoB.

The transformation of the layered precursors into tectomanganates was achieved using a reflux process (Feng et al., 2004). Briefly, the wet layered precursor was dispersed in $400 \mathrm{~mL}$ of $1 \mathrm{M} \mathrm{MgCl}_{2}$ solution, stirred for $12 \mathrm{~h}$ at room temperature, and then washed 3 times. The resulting wet slurry was re-suspended in $500 \mathrm{~mL}$ deionized water in a $1 \mathrm{~L}$ triangle flask connected to a glass condenser with an oil bath kept at $100{ }^{\circ} \mathrm{C}$ and stirred for $24 \mathrm{~h}$. After cooling to room temperature, the reflux products were separated from the solution by filtration, washed 3 times with deionized water and dried at $60^{\circ} \mathrm{C}$ for 3 days. Transformation products of Bir, CoB5, CoB10, CoB15 and CoB20 are named Tod, CoT5, CoT10, CoT15 and CoT20, respectively, and the Co-containing reflux products are collectively referred to as CoT.

After the reflux procedure and when the reflux solutions were at room temperature $\left(23{ }^{\circ} \mathrm{C}\right)$, the conductivity of these solutions was measured with a LeiCi DDS-11A conductimeter. All solid samples were ground in an agate mortar to particle sizes below 100 micron mesh to perform measurements described in Section 2.2. The elemental composition of all solid samples was determined in triplicate via atomic absorption spectrometry (Varian AAS 240FS). Actual $\mathrm{Co} /(\mathrm{Mn}+\mathrm{Co})$ mole ratios in the Co-containing birnessites and reflux products are shown in Table 1. Co K-edge X-ray absorption near edge structure (XANES) spectra that confirm the presence of Co(III) in the layered precursors and reflux products are shown in Figure S1 (Supplementary 
Information).

\subsection{Characterization of layered precursors and reflux products}

217 The mineralogy of all samples was determined by powder XRD, collected on a 218 Bruker D8 Advance diffractometer with $\mathrm{Cu} \mathrm{K \alpha}$ radiation $(\lambda=0.15418 \mathrm{~nm})$, operated at $21940 \mathrm{kV} / 40 \mathrm{~mA}$ and at a scan rate of $1 \%$ min with a $0.02^{\circ}$ step. FTIR spectroscopy was 220 also performed, using a Bruker VERTEX 70. Prior to spectra acquisition, samples 221 were mixed with $\mathrm{KBr}$ in a 1:80 ratio and then pressed into transparent slices. Spectra 222 were recorded over $4000-400 \mathrm{~cm}^{-1}$ with a resolution of $1 \mathrm{~cm}^{-1}$ and with an average of 22364 scans per sample (Zhao et al., 2015). Because it can be difficult to distinguish 224 tectomanganate from buserite, lithiophorite- or asbolane-like phases using XRD (e.g., 225 Burns et al., 1983, 1985; Bodeï et al., 2007; Saratovsky et al., 2009; Feng et al., 2010) 226 we also performed a non-reducing nitric acid wash. This acid wash removes 227 exchangeable species present in the interlayers of phyllomanganates and the tunnels 228 of tectomanganates and so together with XRD provides information on mineral 229 composition and structure. Specifically, after the loss of exchangeable species the 230 d-spacing of phyllomanganates decreases from $\sim 10 \AA$ to $\sim 7 \AA$, while that of 231 todorokite remains stable. The acid wash also removes sorbed species and therefore 232 the composition of the wash solution provides information on the crystal chemistry of 233 Mn and Co, for example, whether Co is sorbed or structurally incorporated. The acid 234 wash was conducted by adding $0.1 \mathrm{~g}$ sample into $250 \mathrm{~mL} 1 \mathrm{M} \mathrm{HNO}_{3}$ solution with 235 moderate stirring at room temperature $\left(20^{\circ} \mathrm{C}\right)$. An aliquot of $5 \mathrm{~mL}$ of the mixtures 236 was withdrawn at different time intervals and immediately filtered through a $0.22 \mu \mathrm{m}$ 237 membrane to investigate the release of $\mathrm{Mg}, \mathrm{Mn}$ and $\mathrm{Co}$, the contents of which were 238 analyzed by atomic absorption spectrometry.

239 The specific surface area of the reflux products was determined by the 240 Brunauer-Emmett-Teller (BET) method using an Autosorb-1 standard physical 241 adsorption analyzer (Quantachrome Autosorb-1, JEDL-6390/LV). Briefly, $0.15 \mathrm{~g}$ of 
sample was degassed at $110{ }^{\circ} \mathrm{C}$ for $3 \mathrm{~h}$ under vacuum prior to $\mathrm{N}_{2}$ adsorption. The

243 micromorphology of the reflux products was imaged with HRTEM on a Jeol 244 JEM2100F operated at $200 \mathrm{kV}$.

245 The Mn and Co local environments in the layered precursors and reflux products 246 were investigated using Mn and Co K-edge EXAFS spectroscopy. Spectra were 247 collected at room temperature on the 1W1B beamline of the Beijing Synchrotron 248 Radiation Facility (BSRF). Data were recorded in transmission mode (Mn K-edge) or 249 fluorescence yield mode (Co K-edge), and the spectrum of a metallic Mn or Co foil 250 was acquired simultaneously in transmission mode as a reference for energy 251 calibration, respectively. The EXAFS spectra were processed via Athena, and fit using 252 Artemis (Ravel and Newville, 2006). The Mn spectra were fit in R-space $(R+\Delta R)$ 253 from 1 to $4 \AA\left(3.06-12.7 \AA^{-1}\right)$, with an amplitude reduction factor $\left(\mathrm{S}_{0}^{2}\right)$ of 0.8 254 (Grangeon et al., 2010). The Co spectra were also fit in $\mathrm{R}$-space $(\mathrm{R}+\Delta \mathrm{R})$ from 1 to 4 $255 \AA\left(3.2-11.5 \AA^{-1}\right)$, with an amplitude reduction factor $\left(\mathrm{S}_{0}^{2}\right)$ of 0.973 (Yin et al., 2014, 256 2015). Both the Mn and Co K-edge fits used scattering paths calculated from Mn/Co 257 atoms in the Mn2 site in todorokite (JCPDS 38-0475), which contains both edge- and 258 corner-sharing linkages. The Mn K-edge EXAFS spectra were also fit in Athena to 259 determine the proportions of $9.6 \AA$ phyllomanganate and tectomanganate in the reflux 260 products. To do this, linear combination fitting of Mn K-edge EXAFS spectra was 261 performed from 3 to $12 \AA^{-1}$, using CoT5 and corresponding CoB as standard samples 262 for Co-containing tunnel and layered structures.

263 The Mn average oxidation state (AOS) in the layered precursors and reflux 264 products was determined by applying a linear combination fitting method to the Mn 265 K-edge XANES data, that is specifically designed for the determination of $\mathrm{Mn}$ 266 valence states in mixed-valent Mn oxides (the so-called Combo method; Manceau et 267 al., 2012). The reference compounds used for Mn(II), Mn(III) and Mn(IV) were those 268 used in the original study (Manceau et al., 2012; Table 1). 


\subsection{Mineralogy of layered precursors and reflux products}

\subsubsection{X-ray diffraction}

Birnessite has basal reflections at $\sim 7.2 \AA(001)$ and $\sim 3.6 \AA$ (002) (see triclinic birnessite JCPDS 43-1456 and hexagonal birnessite JCPDS 23-1239), while for the equivalent layered precursor with an expanded interlayer these appear at $~ 9.6 \AA(001)$ and $4.8 \AA$ (002) (see buserite JCPDS 32-1128). Both birnessite and buserite also have $h k$ reflections/bands at $\sim 2.4 \AA$ and $\sim 1.4 \AA$ due to periodicities within the phyllomanganate layers. In common with $\sim 9.6 \AA$ phyllomanganate, the tectomanganate todorokite has peaks at $\sim 9.6 \AA$ (001/100), $\sim 4.8 \AA(002 / 200)$, 2.4-2.5 $\AA(21-1) /(40-1)$ and (210), and 1.4 $\AA$ (020) (see JCPDS 38-475). As such, it can be difficult to distinguish todorokite from $~ 9.6 \AA$ phyllomanganate using XRD (e.g., Burns et al., 1983, 1985; Bodeï et al., 2007; Saratovsky et al., 2009; Feng et al., 2010). However, in contrast to $\sim 9.6 \AA$ phyllomanganate, todorokite has additional peaks at $2.21 \AA$ (21-2), $1.95 \AA$ (21-3), $1.73 \AA$ (313) and $1.52 \AA$ (21-5) (see JCPDS 38-475). In addition, when $\sim 9.6 \AA$ layered precursors and todorokite reflux products are mixed, the $\sim 2.4 \AA$ peak is prominent and the $\sim 2.5 \AA$ peak manifests as a splitting of the $\sim 2.4 \AA$ peak (Atkins at al., 2014).

The XRD pattern of Bir (Fig. 2a) is in good agreement with that of standard triclinic birnessite (JCPDS 43-1456). The patterns of the CoB samples are very similar to Bir over the low-angle region $5-30^{\circ} 2 \theta$ ), but show significant differences in the high-angle region $\left(30-85^{\circ} 2 \theta\right)$ as the (200), (201), (202), (31-1) and (31-2) reflections of triclinic birnessite at $35.7^{\circ}, 40.1^{\circ}, 48.7^{\circ}, 62.9^{\circ}$, and $64.5^{\circ}(2 \theta \mathrm{Cu} \mathrm{K} \alpha)$, respectively, are weak or absent (Fig. 2a). Cell parameters derived from Rietveld refinement (Fig. S2) show that unit-cell parameter $a$ gradually decreases from $5.171 \AA$ (Bir) to $4.956 \AA$ (CoB20), while other parameters remain stable. As a result, the $a / b$ ratio decreases from 1.818 to 1.736 (Table 2). Taken together, these changes indicate that the layer symmetry of Bir, CoB5 and CoB10 is orthogonal $(a / b>\sqrt{ } 3)$, while the 
layer symmetry of CoB15 and CoB20 is hexagonal $(a / b \approx \sqrt{3})$, as reported in Yin et al.

298 (2015). The orthogonal layer symmetry in Bir is associated with the substitution of $299 \operatorname{Mn}(\mathrm{III})(0.58 \AA$, low spin) for $\operatorname{Mn}(\mathrm{IV})(0.53 \AA$ ) (Manceau et al., 1997), and the systematic elongation of Jahn-Teller distorted $\mathrm{Mn}(\mathrm{III})$ octahedra parallel to the $\boldsymbol{a}^{*}$ 301 axis (Gaillot et al., 2007). Here, hexagonal symmetry is likely caused by the replacement of $\mathrm{Mn}(\mathrm{III})$ by $\mathrm{Co}(\mathrm{III})$ in the layer, where the ionic radius of $\mathrm{Co}(\mathrm{III})$ (0.54

$303 \AA$, low spin) is sufficiently similar to that of $\mathrm{Mn}(\mathrm{III})$ to allow isomorphic substitution 304 (Yin et al., 2015). With an increase in Co content however, the peaks of the CoB 305 samples shift to higher angles, compared to Bir, and this is enhanced in the high-angle region (Fig. 3a). This shift in the XRD peaks occurs because Co(III) has a smaller 307 ionic radius compared to $\mathrm{Mn}(\mathrm{III})$.

308 The XRD pattern of Tod (Fig. 2b) is typical of todorokite with characteristic peaks 309 at $2.21 \AA$ (21-2), $1.95 \AA$ (21-3), $1.73 \AA$ (313) and 1.52 $\AA$ (21-5) (JCPDS 38-475).

310 Natural todorokite can also display distinct peaks at $\sim 7.0 \AA\left(12-14^{\circ} 2 \theta\right)$ and $\sim 4.3 \AA$ 311 (19-21.5 $2 \theta)$ (Post et al., 2003; Bodeï et al., 2007; Manceau et al., 2007). These 312 reflections include $(10-1)\left(12.5^{\circ}\right)$ and $(101)\left(13.5^{\circ}\right)$, and (20-1) $\left(19.8^{\circ}\right),(10-2)\left(20.1^{\circ}\right)$, $313(201)\left(21.0^{\circ}\right)$ and $(102)\left(21.3^{\circ}\right)$ (JCPDS 38-475). As shown in Figure 4, these 314 reflections are parallel to the $\boldsymbol{b}^{*}$ axis and connect the corner site of the todorokite 315 structure with the center of the non-adjacent wall, or the diagonal corner site. As such, 316 the geometry of these crystal planes can be used to represent the periodicity of ideal $3173 \times 3$ todorokite tunnel size. The Tod XRD pattern exhibits a broad hump at $\sim 7 \AA$ and a 318 shoulder at $\sim 4.3 \AA$ rather than distinct peaks, and Tod might therefore possess 319 non-ideal $3 \times n$ tunnel structure. The patterns of the CoT samples are very similar to 320 that of Tod, but the broad hump at $\sim 7 \AA$ is very weak, and the shoulder at $\sim 4.3 \AA$ is 321 weak or absent (Fig. 3b). The CoT samples might therefore exhibit fewer ideal $3 \times 3$ 322 tunnels and more non-ideal $3 \times n$ tunnels compared to Tod. Furthermore, in the CoT 323 samples, the $2.39 \AA$ peak is prominent and the $2.46 \AA$ peak, whose intensity increases 324 with increasing Co content, appears as a splitting of the $2.39 \AA$ peak (Fig. 2b). This 
suggests that the reflux products contain a mixture of $\sim 9.6 \AA$ layered structures and 326 todorokite-like tunnel structures (Atkins et al., 2014). With an increase in Co content, 327 the high-angle peaks of the CoT samples shift to higher angles compared to Tod (Fig. 328 2b), while the low-angle peaks shift to lower angles and sharpen (Fig. 3c), consistent 329 with previous reports (Song et al., 2010). These contrasting changes relative to Tod in 330 the high- and low-angle regions of the CoT XRD patterns indicate that Co 331 incorporation causes a shrinkage of the $\left[\mathrm{MnO}_{6}\right]$ octahedral sheets, but an expansion of 332 the distances between tunnel walls or ceilings, and/or adjacent phyllomanganate 333 layers (Grangeon et al., 2010). We do not observe any peaks attributable to other 334 Co-containing phases in the layered precursors or the reflux products.

\subsubsection{Fourier-transform infrared spectroscopy}

In FTIR spectra of Mn oxides, the broad peak at $\sim 761 \mathrm{~cm}^{-1}$ is attributed to the presence of an asymmetric $\mathrm{Mn}-\mathrm{O}$ stretch from the triple chains of the todorokite 339 lattice (Julien et al., 2004). This absorption band is therefore absent in 340 phyllomanganates and tectomanganates with $1 \times 1$ or $2 \times 2$ tunnel sizes and is unique 341 to both ideal $(3 \times 3)$ and non-ideal $(3 \times \mathrm{n}, \mathrm{n}>3)$ todorokite (Julien et al., 2004). In 342 agreement with XRD data, FTIR results show that all reflux products contain 343 todorokite-like structures as evidenced by the presence of this peak at $\sim 761 \mathrm{~cm}^{-1}$ (Fig. 344 5) (Julien et al., 2004; Atkins et al., 2014; Zhao et al., 2015). The intensity of this peak decreases with Co loading, however, suggesting that the proportion of todorokite-like

346 structures in the reflux products decreases with increasing Co content.

\subsubsection{Nitric acid treatment}

349 The XRD patterns (Fig. 6a) of the layered precursors after $1 \mathrm{M} \mathrm{HNO}_{3}$ treatment

350 for 1 week show reflections at $\sim 2.33,2.04,1.72 \AA$ and a more notable peak at $2.46 \AA$ 351 compared to the untreated samples, corresponding to the characteristic diffraction 352 peaks of hexagonal birnessite (JCPDS 23-1239) (Lanson et al., 2000). These 
differences in the XRD patterns between the layered precursors before and after 354 treatment are most likely related to mineralogical changes resulting from metal release into solution and/or the disproportionation of $\mathrm{Mn}(\mathrm{III})$ and its subsequent 356 migration from layer to interlayer sites during the acid treatment. The concentrations 357 of $\mathrm{Mn}$, Co and $\mathrm{Mg}$ measured in solution during the acid treatment are shown in Figure 3587 as a fraction of their total content $\left(\mathrm{Me}_{\chi}\right.$ where $\mathrm{Me}=\mathrm{Mn}, \mathrm{Co}$ or $\left.\mathrm{Mg}\right)$. The fraction of 359 Mn released for all the layered precursors and reflux products is low (Fig. 7a, b) 360 indicating that dissolution of the Mn oxide framework during the acid treatment is 361 limited. As the acid treatment progresses, for each layered precursor, $\operatorname{Mn}_{\chi}($ Fig. 7a) 362 is relatively constant and the final dissolved ratio is generally negatively correlated to 363 the Co content in the samples. This negative correlation might be related to the 364 amount of $\mathrm{Mn}$ that is sorbed, where, as Co content increases less $\mathrm{Mn}$ is sorbed and 365 thus less $\mathrm{Mn}$ is readily removed during the acid treatment. This is potentially 366 corroborated by the Mn AOS (Table 4) which show that as Co content increases there 367 is reduced $\mathrm{Mn}(\mathrm{III})$ content. In contrast, $\mathrm{Co}_{\chi}$ increases systematically with time (Fig. 368 7c), and $\mathrm{Co}_{\chi}$ for $\mathrm{CoB} 10, \mathrm{CoB} 15$ and $\mathrm{CoB} 20$ are very similar during the entire 369 treatment while $\mathrm{Co}_{\chi}$ for CoB5 is markedly increased, compared to CoB10, CoB15 and $370 \mathrm{CoB} 20$. The limited release of Co from the $\mathrm{CoB}$ layered precursors suggests that Co is 371 to a large extent structurally incorporated in the octahedral layers, and that the 372 proportion of such incorporated Co increases with increasing Co content.

373 The XRD patterns of Tod and CoT5 (Fig. 6b) after being treated in $1 \mathrm{M} \mathrm{HNO}_{3}$ for 3741 week are not significantly different compared to the untreated samples, whereas 375 CoT10, CoT15 and CoT20 show additional peaks at $\sim 7.2 \AA$ and $\sim 3.6 \AA$, characteristic 376 of birnessite, the intensity of which increases with Co content. For CoT20 the 377 intensity of these two peaks does not change from $0.75 \mathrm{~h}$ to $168 \mathrm{~h}$ treatment (Fig. $6 \mathrm{c}$ ).

378 In contrast to the layered precursors, the $\mathrm{Mn}_{\chi}$ for the reflux products increases over 379 time (Fig. 7b), reaching an approximate plateau after 1 week, but the final dissolved 380 ratio is also negatively correlated with the concentration of Co in the samples. Akin to 
381 the layered precursors, this negative correlation might indicate that as Co content 382 increases less $\mathrm{Mn}$ is sorbed and thus less $\mathrm{Mn}$ is readily removed during the acid 383 treatment. The $\mathrm{Co}_{\chi}$ values for the reflux products (Fig. 7d) are similar to those of the 384 layered precursors in that they systematically increase with time, but again, $\mathrm{Co}_{\chi}$ 385 values are low suggesting that Co is largely structurally incorporated in the reflux 386 products. Finally, the fast and complete release of $\mathrm{Mg}$ to solution (Fig. 7e) indicates 387 that all $\mathrm{Mg}$ is present as exchangeable and/or sorbed cations in the reflux products. As 388 XRD shows the sole presence of $\sim 9.6 \AA$ Mn oxides in the untreated reflux products, 389 the additional presence of $\sim 7.2 \AA$ layered minerals after acid treatment indicates that 390 at least part of the released $\mathrm{Mg}$ was originally located in phyllomanganate interlayers, 391 its release leading to the observed shift of the layer-to-layer distance from $\sim 9.6 \AA$ to $392 \sim 7.2 \AA$. Taken together, the release of $\mathrm{Mg}$ to solution upon acid treatment and the 393 presence of characteristic reflections of birnessite in acid-treated CoT10, CoT15 and 394 CoT20 indicate that CoT10, CoT15 and CoT20 contain a mixture of both layered and 395 tunnel structures, consistent with XRD and FTIR data.

\subsection{Morphology of the reflux products}

398 All reflux products consist of platelets and fibers as shown in HRTEM images 399 (Fig. 8). As expected, Tod occurs mostly as fibrous laths aligned with each other at $400120^{\circ}$ to form large aggregates with a network-like morphology (Fig. 8a, b and c). 401 Both fibrous and trilling patterns are characteristic growth morphologies of todorokite 402 and have been reported in both synthetic and natural samples (e.g., Siegel and Turner, 403 1983; Golden et al., 1986; Feng et al., 2004; Bodeï et al., 2007; Atkins et al., 2014). 404 Overall the Tod fibers (Fig. 8c) exhibit lattice fringes with fringe widths of $\sim 1 \mathrm{~nm}$, 405 which corresponds to $3\left[\mathrm{MnO}_{6}\right]$ octahedra, representing the $3 \times 3$ tunnel size of ideal 406 todorokite. In the network-like plates (Fig. 8b) however, there are incoherent tunnel 407 intergrowths with dimensions of $3 \times 4,3 \times 5,3 \times 7,3 \times 8,3 \times 10$ and $3 \times 12\left[\mathrm{MnO}_{6}\right]$ 408 octahedra, as reported by Feng et al. (1999), indicating that in the trilling intergrowths 
the tunnel size in the $a^{*}$ direction is variable. The observation of these non-ideal $3 \times n$

410 tunnel structures is consistent with the XRD for Tod. The images of the Co-containing 411 reflux products are similar to those of Tod, but CoT samples contain fewer fibers (Fig. $4128 \mathrm{i}$ and $\mathrm{j}$ ) and more plates (Fig. 8d-h). In addition, two kinds of plates, with and 413 without lattice fringes, can be distinguished in the CoT samples. In the plates with 414 lattice fringes there does not appear to be a predominant fringe size. Representative 415 images are shown for CoT5 and CoT20 in Figure 8e, k and 1, with fringe widths 416 corresponding to $3,4,5,6,7,9,10,11,12$ and 13 [ $\left.\mathrm{MnO}_{6}\right]$ octahedra, corresponding 417 to a wide range of $3 \times n(n \geq 3)$ tunnel sizes. The increased abundance of non-ideal $3 \times n$ 418 tunnel sizes, compared to Tod, agrees with the XRD for the CoT samples. Plates with 419 smooth surfaces and without visible lattice fringes are observed in CoT20 (Fig. 8j), 420 both features being characteristic of layered structures. The presence of layered 421 structures in the reflux products is consistent with the XRD, FTIR and acid treatment 422 results. Electron diffraction patterns of representative plates for Tod, CoT5, CoT15 423 and CoT20 (Supplementary Information Fig. S3) are all similar, and show 424 pseudo-hexagonal symmetry due to the fringes arranged in three directions (Golden et al., 1986). The presence of Co in these plates is supported by the energy dispersive spectrometry peak at $\sim 6900 \mathrm{eV}(\mathrm{Co} \mathrm{K \alpha})$ (Supplementary Information Fig. S3).

\subsection{Physicochemical analyses of layered precursors and reflux products}

The elemental composition of the layered precursors and reflux products (Table 4)

430 indicate that as Co content increases in the $\mathrm{CoB}$ and CoT samples the $\mathrm{Mn}$ content 431 decreases significantly, relative to Bir and Tod, respectively. This is likely due to the 432 substitution of Co for Mn in the crystal structure (Loganathan et al., 1973; Onda et al., 433 2007), although there is likely some surface adsorption of Co at the edge sites and/or 434 above and below the vacancy sites (Manceau et al., 1997). It is noticeable that the Mn 435 content in the reflux products shows a greater reduction than in the corresponding 436 layered precursors, with no significant modification of the average oxidation state 
(AOS) of Mn (Table 3). On the other hand, the Co content (wt\% and mol\%) is approximately equivalent or slightly higher in the reflux products compared to their corresponding layered precursors. This may indicate that during reflux more $\mathrm{Mn}$ is

440 lost from the layered precursors relative to Co and that the transformation of the 441 layered precursors into tunnel products favours the structural incorporation of Co.

442 The surface areas of CoT samples are significantly lower than that of Tod (Table 443 4), which might indicate that the todorokite-like product in the CoT samples (or the 444 mixture of the todorokite-like product and layered Mn oxides) has increased particle 445 size compared to Co-free Tod.

446 The conductivity of the reflux solutions measured at the end of the reflux process 447 are 26.4, 23.5, 32.0, 25.6 and $24.8 \mu \mathrm{S} / \mathrm{cm}$ for Tod, CoT5, CoT10, CoT15 and CoT20, 448 respectively, indicating that the release to solution of $\mathrm{Co}, \mathrm{Mn}$ and $\mathrm{Mg}$ and 449 corresponding $\mathrm{OH}$ and residual $\mathrm{Cl}$ anions during todorokite formation was limited. 450 The total concentration of dissolved solids derived from the conductivity values 451 (McNeil and Cox, 2000) is $\sim 20 \mathrm{mg} / \mathrm{L}$, equating to a dissolution of $\sim 8 \mathrm{mg}$ of solid 452 from the initial 5-7 $\mathrm{g}$ used in each reflux.

\subsection{Crystal chemistry of Mn and Co in layered precursors and reflux products}

\subsubsection{Mn K-edge XANES}

The Combo method (Manceau et al., 2012) is applied to fit the first derivatives of 457 the Mn K-edge XANES spectra to determine the proportions of $\mathrm{Mn}(\mathrm{II}), \mathrm{Mn}(\mathrm{III})$ and $458 \mathrm{Mn}(\mathrm{IV})$, and thus the Mn AOS in the layered precursor and reflux minerals. Results 459 are shown in Table 3 and the Supplementary Information (Fig. S4 and Table S1). The $460 \mathrm{CoB}$ and CoT samples possess more Mn(IV) and less Mn(III) relative to Bir and Tod, 461 respectively, slightly increasing the $\mathrm{Mn}$ AOS, consistent with previous reports 462 (Manceau et al., 1997). The decrease in Mn(III) relative to Bir and Tod most likely 463 arises from Co(III) substitution for Mn(III) (Manceau et al., 1997; Song et al., 2010; 464 Simanova and Peña, 2015). The Mn AOS values are not significantly different 
between the layered precursors and their reflux products, however, consistent with previous work (Atkins et al., 2014).

\subsubsection{Mn K-edge EXAFS}

In Mn K-edge EXAFS spectra, the region from 6.5 9.5 $\AA^{-1}$ is especially sensitive to the crystal chemistry of Mn in the Mn oxide structure (McKeown and Post., 2001;

471 Manceau et al., 2002, 2004; Gaillot et al., 2003) and as such it is defined as an 472 “indicator" region for Mn oxides (Marcus et al., 2004; Manceau et al., 2004). The 473 frequency, amplitude and shape of the Mn K-edge EXAFS spectra are similar over the entire wavenumber range for all samples, indicating that they possess a common basic structure (Grangeon et al., 2010; Fig. 9a and b). Notably however, the frequencies of the $\mathrm{CoB}$ and $\mathrm{CoT}$ spectra are right-shifted relative to Bir and Tod spectra, respectively (Fig. 9a and b). In agreement with the Mn AOS results, this is attributed to a decrease in $\mathrm{Mn}(\mathrm{III})$ content (Marcus et al., 2004) and the associated reduction of interatomic distances. Furthermore, the amplitude and shape of the spectra for the layered precursors and reflux products evolve as a function of Co content (Fig. 9a and b).

481 Specifically, with increasing Co content the features at 6.8, 8.0, 9.3 and $10.5 \AA^{-1}$ and 482 the troughs at 7.3, 9.8 and $11.2 \AA^{-1}$ increase in amplitude and become sharper. In 483 particular, for Bir, the features at $\sim 8$ and $\sim 9 \AA^{-1}$ have relatively low amplitude and are 484 split, as expected for triclinic birnessite, reflecting the pseudo-orthogonal layer symmetry in its sheets (Manceau et al., 2004; Webb et al., 2005; Gaillot et al., 2007).

486 With increasing Co content, these features increase in amplitude and become single 487 peaks, as expected for hexagonal birnessite, and consistent with a lower content of 488 Jahn-Teller distorted octahedra in the layer structure (Manceau et al., 2004; Marcus et 489 al., 2004; Gaillot et al., 2007). As such, both the XRD and Mn K-edge EXAFS 490 indicate that the layered precursors evolve from triclinic birnessite (Bir) to hexagonal 491 birnessite (CoB15, CoB20) with increasing Co content. For Tod, the features at $\sim 8$ 492 and $\sim 9 \AA^{-1}$ have relatively low amplitude and the feature at $\sim 9 \AA^{-1}$ is broad with a 
pronounced shoulder on the low wavenumber side, consistent with todorokite spectra

494 (Webb et al., 2005; Feng et al., 2010; Atkins et al., 2014). With increasing Co content these features increase in amplitude and the feature at $\sim 9 \AA^{-1}$ becomes much sharper 496 with a loss of the shoulder shape, resembling more closely the shape expected for 497 layered Mn oxides (McKeown and Post, 2001; Webb et al., 2005). As such, the XRD, 498 FTIR, acid treatment, HRTEM and Mn K-edge EXAFS all indicate that the reflux 499 products contain a mixture of layered and tunnel Mn oxides.

500 Concomitant changes are evident in the Fourier transforms of the CoB and CoT 501 spectra, relative to the Bir and Tod spectra, respectively (Fig. 9c and d). The three 502 peaks at $\sim 1.5, \sim 2.5$ and $\sim 3 \AA(\mathrm{R}+\Delta \mathrm{R})$ are common to layered and tunnel structure $\mathrm{Mn}$ 503 oxides and correspond to the first $\mathrm{Mn}-\mathrm{O}$, first Mn-Me edge-sharing $\left(\mathrm{Mn}-\mathrm{Me}_{\mathrm{E}}\right)$ and 504 second Mn-Me corner-sharing $\left(\mathrm{Mn}_{\mathrm{M}} \mathrm{Me}_{\mathrm{C}}\right)$ shell distances, respectively (e.g., Manceau 505 et al., 1988, 2007; Silvester et al., 1997; Gaillot et al., 2003; Marcus et al., 2004; 506 Peacock and Sherman, 2007b; Peña et al., 2010). The Mn-Me $e_{E}$ distance reflects the 507 interatomic distance between adjacent edge-sharing Mn-Mn octahedra, present in the 508 layers of layered Mn oxides, and in the walls and ceilings of tunnel Mn oxides (Fig. 1). 509 The $\mathrm{Mn}_{\mathrm{M}} \mathrm{Me}_{\mathrm{C}}$ distance reflects the interatomic distance between adjacent 510 corner-sharing Mn-Mn octahedra, which can be present in both layered and tunnel Mn 511 oxides when cations adsorb above/below vacant layer sites and/or at edge sites 512 (Manceau et al., 2007), but are largely present in tunnel Mn oxides due to the 513 configuration of the Mn2 / Mn4 sites (Fig. 1) (Kim et al., 2003; Webb et al., 2005).

514 Notably, the reflux products show a more defined and thus easily identifiable peak at $515 \sim 3 \AA(\mathrm{R}+\Delta \mathrm{R})$ compared to their corresponding layered precursor, but the definition of 516 this feature weakens with increasing Co content. This suggests that the reflux 517 products contain more corner-sharing linkages than their layered precursors, but that 518 the proportion of these linkages, and thus the proportion of todorokite-like structures 519 in the reflux products, decreases with increasing Co content, consistent with FTIR 520 results. 
To interpret the Mn K-edge EXAFS more quantitatively, the spectra were fit using 522 a procedure similar to that of Grangeon et al. (2010). Fit parameters are shown in 523 Table 5 and the Supplementary Information (Fig. S5). The fitting results show that the $524 \mathrm{Mn}^{-\mathrm{Me}_{\mathrm{E}}}$ bond distances of the layered precursors and reflux products steadily 525 decrease with increasing Co content (Table 5 and Fig. 10). This is likely caused by the 526 substitution of smaller $\mathrm{Co}(\mathrm{III})$ for $\mathrm{Mn}(\mathrm{III})$, as also evidenced by the shift towards 527 lower $d$-values of the high-angle XRD peaks for the CoB and CoT samples (Fig. 2).

528 Results also show that the ratio of $\mathrm{Mn}-\mathrm{Me}_{\mathrm{C}}$ to $\mathrm{Mn}-\mathrm{Me}_{\mathrm{E}}\left(\mathrm{CN}_{\mathrm{C}} / \mathrm{CN}_{\mathrm{E}}\right)$ increases from the $529 \mathrm{CoB}$ to CoT samples, and decreases slightly from Co-free Tod to Co-containing 530 CoT20, confirming that the reflux products contain more corner-sharing linkages than 531 their layered precursors, and supporting the inference that the proportion of 532 corner-sharing linkages in the reflux products, and thus of todorokite-like structures, 533 decreases with increasing Co content (Table 5).

534 The Mn K-edge $\chi(\mathrm{k})$ spectra were also fit as a linear combination of the CoT5 and 535 corresponding $\mathrm{CoB}$ spectra, used as reference compounds for tunnel and layered $\mathrm{Mn}$ 536 oxides, respectively, to assess the relative proportions of both components in the reflux 537 products (Table 6 and the Supplementary Information, Fig. S6). Fitting indicates that 538 CoT10, CoT15 and CoT20 contain $\sim 80-70 \%$ layered $\sim 9.6 \AA$ Mn oxide and $\sim 20-30 \%$ 539 tunnel todorokite-like Mn oxide. These values are in good agreement with the 540 proportions of layered and tunnel Mn oxides in natural hydrothermal ferromanganese 541 samples (Atkins et al., 2016). The linear combination fitting results indicate that the 542 proportion of todorokite-like structures in the reflux products decreases with increasing 543 Co content, consistent with the FTIR results and the Mn K-edge EXAFS fitting.

\subsubsection{Co K-edge EXAFS}

546 The frequency, amplitude and shape of the Co K-edge EXAFS spectra, in both k547 and r-space, are very similar to one another for both the layered precursors (except for 548 CoB5 which has low Co content and is therefore poor quality) (Fig. 11a) and the 
reflux products (Fig. 11b). These spectra resemble those collected at the Mn K-edge EXAFS, thus implying that Co possesses a very similar local coordination environment in the layered and reflux samples, and that this environment is similar to that of Mn.

To interpret the Co K-edge EXAFS more quantitatively, spectra are fit using a procedure similar to that of Grangeon et al. (2010). Fit parameters are shown in Table 7 and the Supplementary Information (Fig. S7). In this fitting approach, a $f$ parameter is used to estimate the relative proportion of $\mathrm{Co}$ in $\mathrm{Co}-\mathrm{Me}_{\mathrm{E}}$ edge-sharing configuration in the $\mathrm{CoB}$ and $\mathrm{CoT}$ samples (Table 7). Similar to the Mn K-edge spectra, the Co-Me $\mathrm{E}_{\mathrm{E}}$ edge-sharing peak reflects the interatomic distance between adjacent edge-sharing Co-Me octahedra, and can result from the incorporation of Co into the layers of layered Mn oxides (where Co should be surrounded by 6 edge-sharing $\mathrm{Mn}$ ), and the incorporation of Co into the walls or ceilings of tunnel $\mathrm{Mn}$ oxides (where Co at the Mn1 / Mn3 site should be surrounded by 6 edge-sharing Mn, while Co at the Mn2 / Mn4 site should be surrounded by 4 edge-sharing Mn) (Fig. 1). As such the relative proportion of $\mathrm{Co}$ in $\mathrm{Co}-\mathrm{Me}_{\mathrm{E}}$ edge-sharing configuration represents the total proportion of Co that is structurally incorporated in the layered precursors and combined layered and tunnel structure reflux products. The Co-Me corner-sharing peak reflects the interatomic distance between corner-sharing $\mathrm{Co}-\mathrm{Me}$ octahedra, and can result from the surface adsorption of Co at triple corner and/or edge sites on layered and tunnel Mn oxides, and from the incorporation of Co into the walls or ceilings of tunnel Mn oxides (at the Mn2 / Mn4 site where Co should be surrounded by 4 corner-sharing Mn) (Fig. 1). For all samples, data was fit assuming that the coordination number of $\mathrm{Co}$ in $\mathrm{Co}-\mathrm{Me}_{\mathrm{E}}$ edge-sharing configuration is 6 . This might lead to an overestimation of $\mathrm{Co}$ in $\mathrm{Co}-\mathrm{Me}_{\mathrm{E}}$ edge-sharing configuration, and thus of Co that is structurally incorporated in the CoT samples, because Co incorporated into tunnel structures might occupy the Mn2 / Mn4 site with a Co-Me $\mathrm{E}_{\mathrm{E}}$ edge-sharing coordination number of 4 (Song et al., 2010). In this case the Co-Me $\mathrm{E}_{\mathrm{E}}$ edge-sharing 
coordination number for the CoT samples would be slightly less than 6 , and equate to the weighted average of the proportion of Co at the Mn1 / Mn3 site, surrounded by 6 edge-sharing Mn, and Co at the Mn2 / Mn4 site, surrounded by 4 edge-sharing Mn.

Despite this limitation, the approach provides a reasonable estimate of the ratio of Co in $\mathrm{Co}-\mathrm{Me}_{\mathrm{E}}$ edge-sharing configuration and thus the proportion of $\mathrm{Co}$ that is structurally incorporated in the layered precursors and the combined layered and tunnel structure reflux products.

Fitting results show that $\mathrm{Co}-\mathrm{Me}_{\mathrm{E}}$ bond distances of the layered precursors and reflux products do not significantly change with increasing Co content (Table 7 and Fig. 10), indicating that Co incorporated into the precursor and reflux products is uniformly distributed in the crystals, being mainly surrounded by Mn(IV). Results also show that the $f$ parameter, and thus the proportion of nominally structurally incorporated $\mathrm{Co}$, is almost equivalent for the $\mathrm{CoB}$ and CoT samples at $\sim 80 \%$ (Table 7). For the CoB samples, the distribution of Co between incorporated ( $80 \%)$ and surface adsorbed ( 20\%) species is consistent with previous reports (Manceau et al., 1997; Kwon et al., 2013; Yin et al., 2013, 2015). For the CoT samples, which contain a mixture of layered $(\sim 80-70 \%)$ and tunnel ( 20-30\%) structure Mn oxides, the distribution of Co between incorporated $(\sim 80 \%)$ and surface $(\sim 20 \%)$ species reflects the average coordination environment. Given the limitations of the fitting approach, the proportion of the total Co incorporated into the CoT samples might be less than $\sim 80 \%$.

\section{DISCUSSION}

\subsection{Effect of Co on the transformation of birnessite to todorokite}

Layered birnessite precursors with a range of Co contents from 0 to 20 $\mathrm{Co} /(\mathrm{Mn}+\mathrm{Co}) \mathrm{mol} \%$ were subjected to a reflux process designed to simulate the transformation of birnessite into todorokite in natural environments. Of the total Co sorbed in the layered birnessite precursors, $~ 80 \%$ is structurally incorporated and $~ 20 \%$ 
605 is surface adsorbed. Mineralogical data derived from XRD, FTIR, and acid treatment, 606 combined with morphological data from HRTEM and molecular level data from Mn 607 K-edge EXAFS indicate that, for the Co-free birnessite precursor, the reflux 608 procedure produces a todorokite-like product with dominant ideal $3 \times 3$ tunnel sizes in 609 fibrous laths and non-ideal $3 \times n(n \geq 3)$ tunnel sizes in trillings. In contrast, for the 610 Co-containing birnessite precursors, the reflux procedure leads to todorokite-like 611 products with a wide range of non-ideal $3 \times n(n \geq 3)$ tunnel sizes, with no apparent 612 predominant tunnel dimension. Furthermore, for the Co-containing birnessite 613 precursors, the reflux procedure yields Mn oxides with both $~ 9.6 \AA$ layered structure 614 and todorokite-like tunnel structure, in which the proportion of tunnel structures 615 decreases with increasing precursor Co content. These results indicate that the 616 presence of Co in birnessite disrupts its transformation to todorokite.

617 The ability of Co to disrupt the transformation of birnessite into todorokite and 618 produce a non-ideal todorokite-like product is very similar to that of $\mathrm{Ni}$ and can be 619 attributed to the fact that both $\mathrm{Ni}(\mathrm{II})$ and $\mathrm{Co}(\mathrm{III})$ are not Jahn-Teller distorted cations. 620 The presence of Jahn-Teller distorted Mn(III) in the birnessite layers is critical to the 621 transformation of birnessite into todorokite because distortion of the $\mathrm{Mn}$ (III) 622 octahedral due to the Jahn-Teller effect results in an elongation and thus weakening of 623 the $\mathrm{Mn}(\mathrm{III})-\mathrm{O}$ bonds (Bodeï et al., 2007; Cui et al., 2008; Atkins et al., 2014; 624 Grangeon et al., 2014, 2015; Zhao et al., 2015). It is at this structurally weak point 625 that phyllomanganate layers are most susceptible to kinking which leads to the 626 formation of the todorokite tunnel walls within the phyllomanganate interlayers 627 (Atkins et al., 2014; Grangeon et al. 2014). Isomorphic substitution of Jahn-Teller 628 distorted $\mathrm{Mn}(\mathrm{III})$ by $\mathrm{Co}(\mathrm{III})$ therefore reduces the likelihood of todorokite formation 629 (Atkins et al., 2014; 2016). It is possible that the isomorphic substitution of Mn(III) 630 by $\mathrm{Co}(\mathrm{III})$ results in an uneven distribution of $\mathrm{Mn}$ (III) within the layers (Grangeon et 631 al., 2015). This might explain the fact that even the most Co-enriched birnessite 632 precursors are able to form a significant proportion of tunnel structures, but that these 
tunnel structures have non-ideal tunnel dimensions $3 \times n$ (n>>3 - CoT15 and CoT20, with $n$ up to 13). It is noteworthy that ideal $3 \times 3$ tunnel structures are visible in the fibrous laths of the Co-free todorokite reflux product, whereas non-ideal $3 \times n(n>>3)$ tunnel structures dominate in trilling intergrowths of the Co-containing todorokite-like reflux products. Other studies have also noted the predominance of ideal $3 \times 3$ tunnel dimensions in fibrous todorokite (Golden et al., 1986; Post et al., 2003; Feng et al., 2004; Cui et al., 2009). This suggests that ideal todorokite tends to exhibit a fibrous morphology while non-ideal or $\boldsymbol{a}$-disordered todorokite prefers to form trilling intergrowths, and that the presence of Co(III), and likely of other structurally incorporated non Jahn-Teller distorted cations, promotes the formation of a network-like platy morphology over a fibrous one.

In addition to the ability of $\mathrm{Co}(\mathrm{III})$ to disrupt the transformation of birnessite into todorokite, the interlayer species in the precursor layered phase may also be important for transformation. In this work a $\sim 9.6 \AA$ layered precursor with interlayer Mg was synthesized, and the acid treatment indicates that the reflux products with layered structures also contain $\mathrm{Mg}$ as the interlayer species. In the layered precursors, $\mathrm{Mg}$ is likely present in a hydrated form as $\mathrm{Mg}\left(\mathrm{H}_{2} \mathrm{O}\right)_{6}{ }^{2+}$, as for buserite (Shen et al., 1994; Post et al., 2003), but under reflux treatment these species might convert to a $\mathrm{Mg}$ (hydr)oxide, leading to an asbolane-like structure with islands of (hydr)oxides in the interlayer (Chukhrov et al., 1982, 1987; Manceau et al., 1987, 1992). Interestingly, although the acid treatment results in the dissolution of $\mathrm{Mg}$ and the collapse of the reflux product interlayers from $\sim 9.6$ to $\sim 7.2 \AA$, it cannot distinguish between $\mathrm{Mg}\left(\mathrm{H}_{2} \mathrm{O}\right)_{6}{ }^{2+}$ and $\mathrm{Mg}$ (hydr)oxides as both are expected to dissolve and/or to be exchanged under acidic conditions. XRD patterns of reflux products prepared as in the present study and heat treated at $120{ }^{\circ} \mathrm{C}$ for $12 \mathrm{hrs}$ do not show a $\sim 7.2 \AA$ peak (Song et al., 2010), however, as would be expected from the dehydration of $\mathrm{Mg}\left(\mathrm{H}_{2} \mathrm{O}\right)_{6}{ }^{2+}$ interlayer species (Chukhrov et al., 1987; Shen et al., 1994). The interlayer $\mathrm{Mg}$ species in the layered reflux products is therefore resistant to thermal 
661 dehydration and thus most likely resembles a (hydr)oxide-like species, similar to the 662 islands of $\mathrm{Co} / \mathrm{Ni}$ (hydr)oxides present in the interlayers of asbolane (Chukhrov et al., 663 1982, 1987; Manceau et al., 1987, 1992). The formation of Mg (hydr)oxides 664 sandwiched between phyllomanganate layers should result in a slightly higher $665 \mathrm{~d}$-spacing for the layered reflux product compared to todorokite, and thus might 666 explain the shift to higher d-values of the low-angle $00 l$ peaks in the XRD patterns of 667 the reflux products (Fig. 3c). Overall, we suggest that the formation of $\mathrm{Mg}$ 668 (hydr)oxides during the reflux procedure results in a mixture of stabilized $\sim 9.6 \AA$ 669 asbolane-like layered structures and non-ideal todorokite-like tunnel structures in the 670 reflux products.

671 The fact that $\mathrm{Co}(\mathrm{III})$, and other non Jahn-Teller distorted cations, structurally 672 incorporated into birnessite disrupts the transformation of birnessite into todorokite 673 might help explain the often observed predominance of phyllomanganates over 674 tectomanganates in terrestrial and marine environments (e.g., Post, 1999; Marcus et 675 al., 2004; Bodeï et al., 2007; Manceau et al., 2014), and the persistence of 676 phyllomanganates in marine ferromanganese nodules and crusts that are many 677 millions of years old (e.g., Burns and Burns, 1977).

4.2 Implications for the mobility and fate of Co during the transformation of birnessite to todorokite

681 To date only a limited number of studies have investigated the transformation of 682 Co-containing layered Mn oxides into tunnel Mn oxides and the results indicate that 683 precursor Co might be structurally incorporated into newly formed todorokite, by 684 replacing Mn (Ching et al., 1999; Kumagai et al., 2005; Onda et al., 2007; Song et al., 685 2010). In particular, Song et al. (2010) hypothesize that Co primarily substitutes for $686 \mathrm{Mn}(\mathrm{III})$ in Co-containing todorokite, and that these $\mathrm{Mn}(\mathrm{III})$ are likely located at the 687 edge sites (Mn2 and Mn4, Fig. 1) of the ideal 3×3 tunnel structure. As such Co(III) 688 might be primarily incorporated at these edge sites (Ostwald, 1986; Song et al., 2010). 
689 The mineralogical, morphological and molecular level data obtained in the present 690 study indicate that $\mathrm{Co}(\mathrm{III})$ is structurally incorporated into a mixture of $\sim 9.6 \AA$ 691 asbolane-like and todorokite-like reflux products. Specifically, the shifts in the XRD 692 patterns observed for the Co-containing reflux products, and the HRTEM images 693 showing an enhanced occurrence of non-ideal $3 \times n$, or $\boldsymbol{a}$-disordered, todorokite with 694 larger $n$ ( $n$ up to 13), compared to Co-free todorokite, are both consistent with the 695 presence of $\mathrm{Co}(\mathrm{III})$ isomorphically substituted for $\mathrm{Mn}$ (III). It is noteworthy that, 696 eventually, as $n$ approaches $\infty$ these tunnel structures will essentially become 697 layered ones. This evolution is accompanied by an increased occurrence of plate-like 698 network morphologies at the expense of fibrous ones. Consistent with these 699 observations, the Co K-edge EXAFS data shows that $\mathrm{Co}(\mathrm{III})$ is predominantly present 700 as a structurally incorporated species ( $80 \%)$ in the mixed layered and tunnel $\mathrm{Mn}$ 701 oxide reflux products. The EXAFS fitting procedure can to some extent differentiate 702 between Co that is structurally incorporated at the Mn1 / Mn3 sites vs. the Mn2 / Mn4 703 sites of the newly formed tunnel structures (Fig. 1) because it provides an estimate of 704 the ratio of $\mathrm{Co}$ in $\mathrm{Co}-\mathrm{Me}_{\mathrm{E}}$ edge-sharing configuration compared to $\mathrm{Co}$ in $\mathrm{Co}-\mathrm{Me}_{\mathrm{C}}$ 705 corner-sharing configuration. The $\mathrm{Co}-\mathrm{Me}_{\mathrm{E}}$ edge-sharing configuration includes $\mathrm{Co}$ 706 incorporated into the layers of layered Mn oxides, effectively in a Mn1 / Mn3 position, 707 and Co incorporated into the walls or ceilings of tunnel Mn oxides, at both the Mn1 / $708 \mathrm{Mn} 3$ site and the Mn2 / Mn4 site. The Co-Me $\mathrm{C}_{\mathrm{C}}$ corner-sharing configuration includes 709 Co surface adsorbed at triple corner and/or edge sites on layered and tunnel $\mathrm{Mn}$ 710 oxides, and Co incorporated into the walls or ceilings of tunnel Mn oxides at the Mn2 711 / Mn4 site. As such if there was a substantially different distribution of Co between 712 the Co-Me $\mathrm{E}_{\mathrm{E}}$ edge-sharing position in the precursors (i.e., Co incorporated in a Mn1 / 713 Mn3 position) and the $\mathrm{Co}-\mathrm{Me}_{\mathrm{E}}$ edge-sharing positions in the reflux products 714 (comprising the Mn1 / Mn3 site and the Mn2 / Mn4 site) then the estimate of the ratio 715 of $\mathrm{Co}$ in $\mathrm{Co}-\mathrm{Me}_{\mathrm{E}}$ edge-sharing configuration (i.e., the $f$ parameter) should change. The 716 fact that it does not is strong evidence that the Co coordination environment is at least 
717 largely similar between the precursors and the reflux products, and thus that the reflux 718 products contain Co structurally incorporated at the Mn1 / Mn3 non-edge sites. 719 Previous reports suggest that Co might be incorporated at the Mn2 / Mn4 edge sites 720 and thus the precise location of structurally incorporated $\mathrm{Co}(\mathrm{III})$ in tunnel structure 721 Mn oxides deserves further research.

722 The above evidence for structural incorporation of $\mathrm{Co}(\mathrm{III})$ in newly formed 723 asbolane-like and todorokite-like $\mathrm{Mn}$ oxides can be combined with the 724 physicochemical analyses to comment on the likely mobility of Co during the 725 transformation process. The EXAFS data analysis shows that, from the Co-containing 726 layered precursors to their corresponding reflux products, the distribution of Co 727 between $\mathrm{Co}-\mathrm{Me}_{\mathrm{E}}$ edge-sharing and $\mathrm{Co}-\mathrm{Me}_{\mathrm{C}}$ corner-sharing configuration does not 728 substantially change, and therefore the relative bulk distribution of Co is very similar. 729 Moreover, the majority of the Co is present in Co-Me $\mathrm{E}_{\mathrm{E}}$ edge-sharing configuration, 730 and is thus structurally incorporated, with only a minor amount of Co present in $731 \mathrm{Co}^{-\mathrm{Me}_{\mathrm{C}}}$ corner-sharing configuration, either structurally incorporated in tunnel 732 structures or surface adsorbed on layered and/or tunnel structures. For a given metal, 733 structurally incorporated species are generally less susceptible to mobilisation than 734 surface adsorbed species that can be desorbed due to fluctuations in environmental 735 conditions ( $\mathrm{pH}$, ionic strength). The transformation process thus appears to maintain 736 the strong sequestration of $\mathrm{Co}$ by $\mathrm{Mn}$ oxides. Furthermore, the conductivity 737 measurements performed on the final reflux solutions indicate that the concentrations 738 of ions in solution after the transformation process are low and thus the mass of Co 739 lost to solution is also low.

740 Taken together these results suggest that $\mathrm{Co}(\mathrm{III})$ associated with layered birnessite 741 precursors is retained in the solid phase during the transformation of 742 birnessite/buserite to mixed $\sim 9.6 \AA$ asbolane-like and todorokite-like products. 743 Despite the common ability of $\mathrm{Ni}(\mathrm{II})$ and $\mathrm{Co}(\mathrm{III})$ to disrupt the transformation of 744 birnessite into todorokite, this result is in stark contrast to the mobility of $\mathrm{Ni}(\mathrm{II})$ 
745 during the transformation, where, with a similar proportion of structurally 746 incorporated to surface adsorbed cation, $\sim 50 \%$ of the $\mathrm{Ni}$ (II) initially associated with 747 the birnessite precursor is released to solution during the transformation (Atkins et al., 748 2016). The difference in the mobility and fate of $\mathrm{Ni}(\mathrm{II})$ and $\mathrm{Co}(\mathrm{III})$ during the 749 phyllomanganate-to-tectomanganate transformation may be attributed to the 750 differences in their ionic radii and charge. Considering the ionic radii of $\mathrm{Ni}$ (II) (0.68 $751 \AA$ ) and $\operatorname{Co}(\mathrm{III})(0.54 \AA$, low spin) compared to $\mathrm{Mn}(\mathrm{III})(0.58 \AA$, low spin), the steric 752 match between $\mathrm{Co}(\mathrm{III})$ and $\mathrm{Mn}(\mathrm{III})$ is favorable over that between $\mathrm{Ni}(\mathrm{II})$ and $\mathrm{Mn}(\mathrm{III})$, 753 and has been cited as a key parameter for Co uptake by and structural incorporation in 754 Mn oxides (Burns, 1976; Manceau et al., 1997). Considering the ionic charge, or 755 electronegativity of $\mathrm{Ni}(\mathrm{II})$ and $\mathrm{Co}(\mathrm{III}), \mathrm{Co}(\mathrm{III})$ possesses a higher electronegativity 756 than $\mathrm{Ni}$ (II) (1.791 vs. 1.574, respectively) and one that is much closer to that of $757 \mathrm{Mn}(\mathrm{III})$ (1.705, low spin) and Mn(IV) (1.923) (Yin et al., 2013), and thus its 758 incorporation maintains better charge balance. Density functional theory modelling of $759 \mathrm{Co}(\mathrm{III})$ and $\mathrm{Ni}(\mathrm{II})$ uptake by birnessite shows that the energy difference between 760 structural incorporation vs. surface adsorption as a triple corner-sharing complex is 761 much lower for $\mathrm{Co}(\mathrm{III})$ compared to $\mathrm{Ni}$ (II) ( $\Delta$-value is $-214 \mathrm{~kJ} / \mathrm{mol} \mathrm{vs.}-23 \mathrm{~kJ} / \mathrm{mol})$. 762 Incorporation of $\mathrm{Co}(\mathrm{III})$ is therefore favoured over $\mathrm{Ni}(\mathrm{II})$ and moreover, this 763 incorporation is favoured over surface adsorption (Kwon et al., 2013).

764 Overall the differences in the ionic properties of $\mathrm{Co}(\mathrm{III})$ and $\mathrm{Ni}(\mathrm{II})$ mean that, 765 although both $\mathrm{Ni}(\mathrm{II})$ and $\mathrm{Co}(\mathrm{III})$ are non Jahn-Teller distorted, $\mathrm{Co}(\mathrm{III})$ provides a 766 more favourable match to the layered and tunnel structure $\mathrm{Mn}(\mathrm{III})$ sites compared to $767 \mathrm{Ni}(\mathrm{II})$, and $\mathrm{Co}(\mathrm{III})$ is therefore incorporated in the mixed layered and newly formed 768 tunnel structures. By comparison, $\sim 50 \%$ of $\mathrm{Ni}(\mathrm{II})$ associated with precursor layer 769 structures is lost to solution during the transformation and the remaining $\mathrm{Ni}$ (II) is only 770 surface adsorbed on newly formed todorokite, meaning that it is susceptible to 771 desorption and loss to solution (Atkins et al., 2016). More generally it is apparent that 772 the mobility and fate of transition metals associated with Mn oxides depends on a 
number of metal properties, including Jahn-Teller distortion, ionic radius and electronegativity, where metal behaviour is selectively dictated by the structure of the Mn oxide. This means that Mn oxides with distinct structures (i.e. layered or tunnel structures) are likely to play unequal roles in the mobility and fate of transition metals in the environment.

\section{SUMMARY AND CONCLUSIONS}

The present study reports the first detailed investigation of the effect of Co content on the transformation of layered precursor Mn oxide birnessite into tunnel structure Mn oxide products, and documents the mobility and fate of Co during the transformation process. The structural incorporation of Co in layered birnessite precursors leads to an overall reduction of Jahn-Teller distorted Mn(III) octahedra in these precursors, a key factor for their transformation to tunnel structures. As a consequence, the presence of such structural Co(III) disrupts the transformation of birnessite into todorokite, leading to the coexistence of a $\sim 9.6 \AA$ asbolane-like phyllomanganate and a non-ideal, or $\boldsymbol{a}$-disordered, todorokite-like tectomanganate. Non-ideal todorokite appears as trilling intergrowths with a wide range of tunnel dimensions that form a network plate-like morphology. Contrary to $\mathrm{Ni}(\mathrm{II})$, which also disrupts the transformation of layered to tunnel structures, $\mathrm{Co}$ (III) is retained in the solid transformation products, predominantly as structurally incorporated species. The results suggest that $\mathrm{Co}(\mathrm{III})$ is likely present in the Mn1 and Mn3 non-edge sites of todorokite, in contrast to previous reports. Overall, the transformation of Co-containing birnessite into todorokite in soils and sediments is unlikely to provide a significant source of Co to soil and sediment porewaters. The present study compared to the results of previous work on the behaviour of other transition metals during the transformation of birnessite to todorokite demonstrates that, overall, metal mobility depends on a specific set of metal properties, the relative importance of these being likely dictated by the structure of the host Mn oxide. 


\section{Acknowledgements}

803 The authors are grateful to Dr. Pengfei An and Yunpeng Liu at Beijing 804 Synchrotron Radiation Facility (BSRF) for their help in X-ray absorption 805 spectroscopy and XRD data collection and analysis. Zhongkuan Wu also thanks Dr. 806 Yuan Chen at Wuhan University for help with English language. This work is 807 supported by the National Key Research and Development Program of China 808 (No.2016YFD0800403) and the Natural Science Foundations of China (No. 80941271253 and U1432104). Caroline L. Peacock was supported by the Royal Society 810 (Newton Mobility Grant No. IE151033). The present study benefited also from a Cai 811 Yuanpei program between the Key Laboratory of Arable Land Conservation (Wuhan, 812 China) and ISTerre (Grenoble, France).

\section{REFERENCES}

815 Atkins A. L., Shaw S. and Peacock C. L. (2014) Nucleation and growth of todorokite 816 from birnessite: implications for tracemetal cycling in marine sediments. 817 Geochim. Cosmochim. Acta 144, 109-125.

818 Atkins A. L., Shaw S. and Peacock C. L. (2016) Release of Ni from birnessite during 819 transformation of birnessite to todorokite: Implications for Ni cycling in marine sediments. Geochim. Cosmochim. Acta. 189, 158-183.

821 Bodeï S., Manceau A., Geoffroy N., Baronnet A. and Buatier M. (2007) Formation of todorokite from vernadite in Ni-rich hemipelagic sediments. Geochim. Cosmochim. Acta. 71, 5698-5716.

824 Burns R. G. (1976). The uptake of cobalt into ferromanganese nodules, soils, and synthetic manganese (IV) oxides. Geochim. Cosmochim. Acta. 40(1), 95-102.

Burns R.G. and Burns V.M. (1975) Mechanism for nucleation and growth of manganese nodules. Nature, 255, 130-131.

828 Burns R. G. and Burns V. M. (1977). The mineralogy and crystal chemistry of 
deep-sea manganese nodules, a polymetallic resource of the twenty-first century. Phil. Trans. R. Soc. London A286, 283-301.

831 Burns R. G., Burns V. M. and Stockman H. W. (1983). A review of the todorokite-buserite problem; implications to the mineralogy of marine manganese nodules. Am. Mineral. 68, 972-980.

Burns R. G., Burns V. M. and Stockman H. W. (1985) The todorokite-buserite problem: further considerations. Am. Mineral. 70, 205-208.

Ching S., Krukowska K. S. and Suib S. L. (1999) A new synthetic route to todorokite-type manganese oxides. Inorg. Chim. Acta. 294, 123-132.

Chukhrov F. V, Drits V. A. and Gorshkov A. I. (1987) Structural transformations of manganese oxides in oceanic nodules. Int. Geol. Rev. 29, 110-121.

Chukhrov F. V., Gorshkov A. I., Vitovskaya I. V., Drits V. A., Sistov A. V. and Rudnitskaya Y. S. (1982) Crystallochemical nature of Co-Ni asbolane. Int. Geol. Rev. 24, 598-604.

Cui H., Feng X., Tan W., He J. Hu R. and Liu F. (2009) Synthesis of todorokite-type manganese oxide from $\mathrm{Cu}$-buserite by controlling the $\mathrm{pH}$ at atmospheric pressure. Micropor. Mesopor. Mat. 117, 41-47.

Cui H., Liu F., Feng X., Tan W. and Wang M. (2010) Aging promotes todorokite formation from layered manganese oxide at near-surface conditions. J. Soil Sediment 10, 1540-1547.

Cui H., Liu X., Tan W., Feng X., Liu F. and Ruan H. D. (2008) Influence of Mn (III) availability on the phase transformation from layered buserite to tunnel-structured todorokite. Clays Clay Miner. 56, 397-403.

Davies S. H. R. and Morgan J. J. (1989) Manganese (II) oxidation kinetics on metal oxide surfaces. J. Colloid Interface Sci. 129, 63-77.

Drits, V.A., Lanson, B., and Gaillot, A.C. (2007) Birnessite polytype systematics and identification by powder X-ray diffraction. Am. Mineral. 92, 771-788.

Drits V. A., Silvester E., Gorshkov A. I. and Manceau A. (1997). Structure of synthetic 
monoclinic Na-rich birnessite and hexagonal birnessite: I. Results from X-ray diffraction and selected-area electron diffraction. Am. Mineral. 82, 946-961.

Dublet G., Juillot F., Brest J., Noel V., Fritsch E., Proux O., Olivi L., Ploquin. and Morin G. (2017). Vertical changes of the Co and Mn speciation along a lateritic regolith developed on peridotites (New Caledonia). Geochim. Cosmochim. Acta. 217, 1-15.

Feng Q., Kanoh H. and Ooi K. (1999) Manganese oxide porous crystals. J. Mater. Chem. 9, 319-333.

Feng X., Tan W., Liu F., Wang J. and Ruans H. (2004) Synthesis of todorokite at atmospheric pressure. Chem. Mater. 16, 4330-4336.

Feng X., Zhu M., Ginder-Vogel M., Ni C., Parikh S. and Sparks D. (2010) Formation of nano-crystalline todorokite from biogenic Mn oxides. Geochim. Cosmochim. Acta. 74, 3232-3245.

Fuller C. C. and Harvey J. W. (2000) Reactive uptake of trace metals in the hyporheic zone of a mining-contaminated stream, Pinal Creek, Arizona. Environ. Sci. Technol. 34, 1150-1155.

Gaillot A. C., Drits V. A., Manceau A. and Lanson B. (2007) Structure of the synthetic K-rich phyllomanganate birnessite obtained by high-temperature decomposition of $\mathrm{KMnO}_{4}$ : Substructures of K-rich birnessite from $1000{ }^{\circ} \mathrm{C}$ experiment. Micropor. Mesopor. Mat. 98, 267-282.

Gaillot A. C., Flot D., Drits V. A., Burghammer M., Manceau A. and Lanson B. (2003) Structure of synthetic K-rich birnessites obtained by high-temperature decomposition of $\mathrm{KMnO}_{4}$. I. Two-layer polytype from a $800^{\circ} \mathrm{C}$ experiment. Chem. Mater. 15, 4666-4678.

Golden D. C., Chen C. C. and Dixon J. B. (1986) Synthesis of todorokite. Science, 231, 717-719.

Grangeon S., Fernandez-Martinez A., Warmont F., Gloter A., Marty N., Poulain A. and Lanson B. (2015) Cryptomelane formation from nanocrystalline vernadite 
precursor: a high energy X-ray scattering and transmission electron microscopy perspective on reaction mechanisms. Geochem. Trans. 16, 12.

Grangeon S., Lanson B. and Lanson M. (2014) Solid-state transformation of nanocrystalline phyllomanganate into tectomanganate: influence of initial layer and interlayer structure. Acta Crystallogr., Sect. B: Struct. 70, 828-838.

Grangeon S., Lanson B., Lanson M., and Manceau A. (2008) Crystal structure of Ni-sorbed synthetic vernadite: a powder X-ray diffraction study. Mineral. Mag. 72, 1279-1291.

Grangeon S., Lanson B., Miyata N., Tani Y. and Manceau A. (2010) Structure of nanocrystalline phyllomanganates produced by freshwater fungi. Am. Mineral. 95, 1608-1616.

Grangeon S., Manceau A., Guilhermet J., Gaillot A.C., Lanson M., and Lanson B. (2012) Zn sorption modifies dynamically the layer and interlayer structure of vernadite. Geochim. Cosmochim. Acta. 85, 302-313

Julien C. M., Massot M. and Poinsignon C. (2004) Lattice vibrations of manganese oxides: Part I. Periodic structures. Spectrochim. Acta. A, 60, 689-700.

Kim H. S., Pasten P. A., Gaillard J. F. and Stair P. C. (2003) Nanocrystalline todorokite-like manganese oxide produced by bacterial catalysis. J. Am. Chem. Soc. 125, 14284-14285.

Kumagai N., Komaba S., Abe K. and Yashiro H. (2005) Synthesis of metal-doped todorokite-type $\mathrm{MnO}_{2}$ and its cathode characteristics for rechargeable lithium batteries. J. Power Sources 146, 310-314.

Kwon K. D., Refson K. and Sposito G. (2013). Understanding the trends in transition metal sorption by vacancy sites in birnessite. Geochim. Cosmochim. Acta. 101, 222-232.

Lanson, B., Drits, V.A., Feng, Q., and Manceau, A. (2002a) Structure of synthetic Na-birnessite: Evidence for a triclinic one-layer unit cell. Am. Mineral. 87, $1662-1671$. 
Lanson B., Drits V. A., Gaillot A. C., Silvester E., Plançon, A. and Manceau A. 914 (2002b). Structure of heavy-metal sorbed birnessite: Part 1. Results from X-ray diffraction. Am. Mineral. 87, 1631-1645.

916 Lanson B., Drits V. A., Silvester E. and Manceau A. (2000). Structure of H-exchanged 917 hexagonal birnessite and its mechanism of formation from Na-rich monoclinic 918 buserite at low pH. Am. Mineral. 85, 826-838.

919 Llorca, S. (1987) Nouvelles données sur la composition et la structure des 920 lithiophorites d'après de échantillons de Nouvelle-Calédonie. C. R. Acad. Sci $921 \quad$ Paris - Série II 304, 15-18.

922 Llorca, S. (1988) Nouvelles données sur la composition et la structure des asbolanes 923 (Nouvelle-Calédonie). C. R. Acad. Sci Paris - Série II 307, 155-161.

924 Loganathan P. and Burau R. G. (1973) Sorption of heavy metal ions by a hydrous 925 manganese oxide. Geochim. Cosmochim. Acta. 37, 1277-1293.

926 Manceau A., Drits V. A., Silvester E., Bartoli C. and Lanson B. (1997) Structural 927 mechanism of $\mathrm{Co}^{2+}$ oxidation by the phyllomanganate buserite. Am. Mineral. 82, $928 \quad 1150-1175$.

929 Manceau, A., Gorshkov, A.I., and Drits, V.A. (1992) Structural Chemistry of Mn, Fe, 930 Co, and Ni in Mn hydrous oxides. II. Information from EXAFS spectroscopy, 931 electron and X-ray diffraction. Am. Mineral. 77, 1144-1157.

932 Manceau A., Kersten M., Marcus M. A., Geoffroy N. and Granina L. (2007) Ba and 933 Ni speciation in a nodule of binary Mn oxide phase composition from Lake $934 \quad$ Baikal. Geochim. Cosmochim. Acta 71, 1967-1981.

935 Manceau A. Lanson M. and Takahashi Y. (2014). Mineralogy and crystal chemistry of $936 \mathrm{Mn}, \mathrm{Fe}, \mathrm{Co}, \mathrm{Ni}$ and $\mathrm{Cu}$ in a deep-sea pacific polymetallic nodule. Am. $937 \quad$ Mineral. 99, 2068-2083.

938 Manceau A., Llorca S. and Calas G. (1987) Crystal chemistry of cobalt and nickel in 939 lithiophorite and asbolane from New Caledonia. Geochim. Cosmochim. Acta. 51, $940 \quad 105-113$. 
941 Manceau A., Marcus M. A. and Grangeon S. (2012) Determination of Mn valence 942 states in mixed-valent manganates by XANES spectroscopy. Am. Mineral. 97, $943 \quad 816-827$.

944 Manceau A., Marcus M. A. and Tamura N. (2002) Quantitative speciation of heavy 945 metals in soils and sediments by synchrotron X-ray techniques. In Applications 946 of Synchrotron Radiation in Low-temperature Geochemistry and Environmental 947 Science, vol. 49 (eds. P.A. Fenter, M.L. Rivers, N.C. Sturchio and S.R. Sutton). $948 \quad$ Springer, pp. 341-428.

949 Manceau A., Tommaseo C., Rihs S., Geoffroy N., Chateigner D., Schlegel M., 950 Tisserand D., Marcus M. A., Tamura N. and Chen Z. S. (2005) Natural speciation 951 of $\mathrm{Mn}, \mathrm{Ni}$ and $\mathrm{Zn}$ at themicrometer scale in a clayey paddy soil using X-ray 952 fluorescence, absorption, and diffraction. Geochim. Cosmochim. Acta 69, 953 4007-4034.

954 Marcus M. A., Manceau A. and Kersten M. (2004) Mn, Fe, Zn and As speciation in a 955 fast-growing ferromanganese marine nodule. Geochim. Cosmochim. Acta 68, 956 957 958 3125-3136

McKeown D. A. and Post J. E. (2001) Characterization of manganese oxide mineralogy in rock varnish and dendrites using X-ray absorption spectroscopy. Am. Mineral. 86, 701-713.

McNeil V. H. and Cox M. E. (2000) Relationship between conductivity and analysed composition in a large set of natural surface-water samples, Queensland, Australia. Environ. Geol. 39, 1325-1333.

Murray J. W. (1975) The interaction of cobalt with hydrous manganese dioxide. Geochim. Cosmochim. Acta 39, 635-647.

Murray J. W., Balistrieri L. S. and Paul B. (1984) The oxidation State of Manganese

968 Murray J. W. and Dillard J. G. (1979) The oxidation of cobalt(II) adsorbed on 

manganese dioxide. Geochim. Cosmochim. Acta 43, 781-787.

970 Nicolas-Tolentino E., Tian Z. R., Zhou H., Xia G. G. and Suib S. L. (1999) Effects of $971 \mathrm{Cu}^{2+}$ ions on the structure and reactivity of todorokite-and cryptomelane-type 972 manganese oxide Octahedral molecular sieves. Chem. Mater. 11, 1733-1741.

973 Onda A., Hara S., Kakiyoshi K. and Yanagisawa K. (2007) Synthesis of manganese oxide octahedral molecular sieves containing cobalt, nickel, or magnesium, and the catalytic properties for hydration of acrylonitrile. Appl. Catal. A 321, 71-78.

Ostwald J. (1984) Two varieties of lithiophorite in some Australian deposits. Mineral. Mag. 48, 383-388.

Ostwald J. (1986) Some observations on the chemical composition of todorokite. 979 Mineral. Mag. 50, 336-340.

980 Peacock C. L. (2009). Physiochemical controls on the crystal-chemistry of Ni in 981 birnessite: genetic implications for ferromanganese precipitates. Geochim. 982 Cosmochim. Acta 73, 3568-3578.

983 Peacock C. L. and Sherman D. M. (2007a) Crystal-chemistry of $\mathrm{Ni}$ in marine 984 ferromanganese crusts and nodules. Am. Mineral. 92, 1087-1092.

985 Peacock C. L. and Sherman D. M. (2007b) Sorption of Ni by birnessite: Equilibrium 986 controls on Ni in seawater. Chem. Geol. 238, 94-106.

987 Peña J., Kwon K. D., Refson K., Bargar J. R. and Sposito G. (2010) Mechanisms of 988 nickel sorption by a bacteriogenic birnessite. Geochim. Cosmochim. Acta 74, 989 3076-3089.

990 Post J. E. (1999) Manganese oxide minerals: crystal structures and economic and 991 environmental significance. Proc. Natl. Acad. Sci. U. S. A. 96, $3447-3454$.

992 Post J. E. and Appleman D. E. (1988) Chalcophanite, $\mathrm{ZnMn}_{3} \mathrm{O}_{7}-3 \mathrm{H}_{2} \mathrm{O}$ : New 993 crystal-structure determinations. Am. Mineral. 73, 1401-1404.

994 Post, J.E. and Appleman, D.E. (1994) Crystal structure refinement of lithiophorite. Am. $995 \quad$ Mineral. 79, 370-374.

996 Post J. E., Heaney P. J. and Hanson J. (2003) Synchrotron X-ray diffraction study of 
the structure and dehydration behaviour of todorokite. Am. Mineral. 88, 142 150.

Ravel B. and Newville M. (2006) Athena and Artemis: interactive graphical data analysis using ifeffit. Phys. Scripta 115, 1007-1010.

1001 Remucal C.K. and Ginder-Vogel, M. (2014) A critical review of the reactivity of manganese oxides with organic contaminants. Environ. Sci. Proc. Impacts 16, $1247-1266$.

1005

Saito M. A. and Moffett J. W. (2002) Temporal and spatial variability of cobalt in the atlantic ocean. Geochim. Cosmochim. Acta 66, 1943-1953.

Saratovsky I., Gurr S. J. and Hayward M. A. (2009). The structure of manganese oxide formed by the fungus Acremonium sp. strain kr21-2. Geochim. Cosmochim. Acta 73, 3291-3300.

Shen X. F., Ding Y. S., Liu J., Cai J., Laubernds K., Zerger R.P., Vasiliev A., Aindow M. and Suib S.L. (2005) Control of Nanometer - Scale Tunnel Sizes of Porous Manganese Oxide Octahedral Molecular Sieve Nanomaterials. Adv. Mater. 17,

Shen Y. F., Suib S L and O'Young C. L. (1994) Effects of inorganic cation templates on octahedral molecular sieves of manganese oxide. J. Am. Chem. Soc. 116, $11020-11029$.

1016 Siegel M. D. and Turner S. (1983) Crystalline todorokite associated with biogenic debris in manganese nodules. Science 219,172-4.

1018 Silvester E., Manceau M. and Drits V. A. (1997) Structure of synthetic monoclinic 1019 Na-rich birnessite and hexagonal birnessite: II. Results from chemical studies and EXAFS spectroscopy. Am. Mineral. 82, 962-978.

1021 Simanova A. A. and Peña J. (2015) Time-resolved investigation of cobalt oxidation by $1022 \mathrm{Mn}$ (III)-rich $\delta-\mathrm{MnO}_{2}$ using quick X-ray absorption spectroscopy. Environ. Sci. 1023 Technol. 49, 10867-10876.

1024 Song C., Li R., Liu F., Feng X., Tan W. and Qiu G. (2010) Cobalt-doped todorokites 
prepared by refluxing at atmospheric pressure as cathode materials for $\mathrm{Li}$ batteries. Electrochim. Acta 55, 9157-9165.

1027

1028

1029

1030

1031

1032

1033

1034

1035

1036

1037

1038

1039

1040

1041

1042

1043

1044

1045

1046

1047

1048

1049

1050

1051

1052

Taylor R. M. (1968). The association of manganese and cobalt in soils-further observations. Eur. J. Soil Sci. 19, 77-80.

Taylor R. M., McKenzie R. M., and Norrish K. (1964) The mineralogy and chemistry of manganese in some Australian soils. Aust. J. Soil Res. 2, 235-248.

Tebo B. M., Bargar J. R., Clement B. G., Dick G. J., Murray K. J., Parker D., Verity R., and Webb S.M. (2004) Biogenic manganese oxides: Properties and mechanisms of formation. Annu. Rev. Earth Pl. Sci. 32, 287-328.

Villalobos M., Bargar J., and Sposito G. (2005) Mechanisms of Pb(II) Sorption on a Biogenic Manganese Oxide. Environ. Sci. Technol. 39, 569-576.

Villalobos M., Lanson B., Manceau A., Toner B., and Sposito G. (2006) Structural model for the biogenic Mn oxide produced by Pseudomonas putida. Am. Mineral. 91, 489-502.

Vodyanitskii Y. N., Vasilev A. A., Lesovaya S. N., Sataev E. F., and Sivtsov, A. V. (2004) Formation of manganese oxides in soils. Eurasian Soil Sci. 37, 572-584.

Webb S. M., Tebo B. M. and Bargar J. R. (2005) Structural characterization of biogenic Mn oxides produced in seawater by the marine Bacillus sp. strain SG-1. Am. Mineral. 90, 1342-1357.

Yin Y. G., Xu W. Q., Shen Y. F., Suib S. L. and O'Young C. L. (1994) Studies of oxygen species in synthetic todorokite-like manganese oxide octahedral molecular sieves. Chem. Mater. 6, 1803-1808.

Yin H., Li H., Wang Y., Ginder-Vogel M., Qiu G., Feng X., Zheng L. and Liu F. (2014) Effects of $\mathrm{Co}$ and $\mathrm{Ni}$ co-doping on the structure and reactivity of hexagonal birnessite. Chem. Geol. 381, 10-20.

Yin H., Liu F., Feng X., Hu T., Zheng L., Qiu G., Koopal L. K. and Tan W. F. (2013). Effects of Fe doping on the structures and properties of hexagonal birnessites comparison with Co and Ni doping. Geochim. Cosmochim. Acta 117, 1-15. 
1053 Yin H., Liu Y., Koopal L. K., Feng X., Chu S., Zhu M. and Liu F. (2015) High 1054 Co-doping promotes the transition of birnessite layer symmetry from orthogonal 1055 to hexagonal. Chem. Geol. 410, 12-20.

1056 Yu Q., Sasaki K., Tanaka K., Ohnuki T. and Hirajima, T. (2012) Structural factors of 1057 biogenic birnessite produced by fungus Paraconiothyrium, sp. wl-2 strain 1058 affecting sorption of $\mathrm{Co}^{2+}$. Chem. Geol. 310-311, 106-113.

1059 Zhao H., Liang X., Yin H., Liu F., Tan W., Qiu G. and Feng X. (2015) Formation of 1060 todorokite from " $c$-disordered" $\mathrm{H}^{+}$-birnessites: the roles of average manganese 1061 oxidation state and interlayer cations. Geochem. Trans. 16, 1-11. 
Table 1

Co wt. \% and Co mole ratio in layered precursors and reflux products

\begin{tabular}{ccc}
\hline Samples & $\begin{array}{c}\text { Co } \\
\text { wt. \% }\end{array}$ & $\begin{array}{c}\mathrm{Co} /(\mathrm{Mn}+\mathrm{Co}) \\
\text { mol \% }\end{array}$ \\
\hline Bir & -- & -- \\
CoB5 & $1.97(2)$ & 3.3 \\
CoB10 & $4.70(5)$ & 7.7 \\
CoB15 & $7.55(4)$ & 12.5 \\
CoB20 & $9.84(7)$ & 16.9 \\
Tod & -- & -- \\
CoT5 & $2.05(4)$ & 3.8 \\
CoT10 & $4.46(6)$ & 8.3 \\
CoT15 & $6.81(8)$ & 13.5 \\
CoT20 & $9.26(12)$ & 17.9 \\
\hline
\end{tabular}

Table 2

Lattice parameters derived from Rietveld refinements* for layered precursors

\begin{tabular}{ccccccc}
\hline Samples & $\mathrm{a} / \AA ̊$ & $\mathrm{~b} / \AA$ & $\mathrm{c} / \AA$ & $\beta /{ }^{\circ}$ & $\mathrm{Rwp} / \%$ & $\mathrm{a} / \mathrm{b}$ \\
\hline $\mathrm{Bir}$ & $5.1710(7)$ & $2.8447(4)$ & $7.3309(9)$ & $103.37(2)$ & 6.94 & 1.818 \\
CoB5 & $5.1212(16)$ & $2.8491(6)$ & $7.3159(11)$ & $102.65(3)$ & 7.96 & 1.798 \\
CoB10 & $5.0134(15)$ & $2.8564(10)$ & $7.2878(18)$ & $101.95(6)$ & 6.08 & 1.755 \\
CoB15 & $4.9649(20)$ & $2.8638(10)$ & $7.2876(13)$ & $102.07(4)$ & 6.85 & 1.734 \\
CoB20 & $4.9562(14)$ & $2.8553(8)$ & $7.2888(13)$ & $102.30(4)$ & 7.23 & 1.736 \\
\hline
\end{tabular}

Note: Birnessite initial structural parameters were adapted from JCPDS 43-1456, and during the refinement process, cell parameters and site occupancy in the $\mathrm{MnO}_{6}$ layer were refined. Co ions in $\mathrm{CoB}$ samples were assumed to substitute for Mn sites in the structure, such that the sum of occupation for Mn and Co was fixed to 1. 
Table 3

Fractional and average valence states of Mn obtained from a Combo fit of Mn K-edge XANES 1st derivative spectra of layered precursors and reflux products. The estimated error for Combo method is $\pm 4 \%$ (Manceau et al., 2012; Yin et al., 2015)

\begin{tabular}{ccccc}
\hline Sample & $\begin{array}{c}\mathrm{Mn}^{2+} \\
\text { at. \% }\end{array}$ & $\begin{array}{c}\mathrm{Mn}^{3+} \\
\text { at. \% }\end{array}$ & $\begin{array}{c}\mathrm{Mn}^{4+} \\
\text { at. \% }\end{array}$ & Mn-AOS \\
\hline Bir & 2 & 26 & 72 & 3.69 \\
CoB5 & 3 & 17 & 81 & 3.78 \\
CoB10 & 4 & 27 & 69 & 3.64 \\
CoB15 & 5 & 7 & 88 & 3.83 \\
CoB20 & 5 & 9 & 86 & 3.80 \\
Tod & 2 & 25 & 74 & 3.72 \\
CoT5 & 2 & 23 & 75 & 3.73 \\
CoT10 & 4 & 26 & 70 & 3.66 \\
CoT15 & 2 & 16 & 82 & 3.81 \\
CoT20 & 5 & 8 & 87 & 3.82 \\
\hline
\end{tabular}

Note: The references used to fit Mn K-edge XANES data are those used by Manceau et al. (2012).

Table 4

Physicochemical properties of layered precursors and reflux products

\begin{tabular}{|c|c|c|c|c|c|}
\hline \multirow{2}{*}{ Samples } & \multirow{2}{*}{$\begin{array}{c}\mathrm{Mn} \\
\text { wt. } \%\end{array}$} & \multirow{2}{*}{$\begin{array}{c}\mathrm{Mg} \\
\text { wt. \% }\end{array}$} & \multicolumn{2}{|c|}{$\mathrm{Mg} / \mathrm{MnMg} /(\mathrm{Mn}+\mathrm{C}$} & \multirow{2}{*}{$\begin{array}{l}\text { SSA } \\
\left(\mathrm{m}^{2} / \mathrm{g}\right)\end{array}$} \\
\hline & & & $\mathrm{mol} \%$ & $\mathrm{~mol} \%$ & \\
\hline Bir & $55.4(1.0)$ & -- & -- & -- & -- \\
\hline CoB5 & $54.0(2.0)$ & -- & -- & -- & -- \\
\hline $\mathrm{CoB} 10$ & $52.3(2.3)$ & -- & -- & -- & -- \\
\hline CoB 15 & 49.2(7) & -- & -- & -- & -- \\
\hline $\mathrm{CoB} 20$ & $45.0(1.8)$ & -- & -- & -- & -- \\
\hline Tod & $54.4(2.1)$ & $3.95(8)$ & 16.4 & 16.4 & 90.7 \\
\hline CoT5 & $48.0(1.2)$ & $3.86(9)$ & 18.2 & 16.9 & 47.6 \\
\hline CoT10 & $46.0(1.5)$ & $3.67(12)$ & 18.1 & 17.5 & 86.2 \\
\hline CoT15 & $40.9(1.2)$ & $3.72(2)$ & 20.6 & 16.6 & 51.1 \\
\hline CoT20 & $39.6(7)$ & $3.58(7)$ & 20.4 & 17.0 & 55.0 \\
\hline
\end{tabular}

Note: Na was not detected in samples prepared by Song et al. (2010) with the same method and thus not measured in the present samples. 
Table 5

Structural parameters derived from Mn K-edge EXAFS fitting over 1-4

\begin{tabular}{|c|c|c|c|c|c|c|c|c|c|c|c|}
\hline Atomic pairs & & Bir & CoB5 & $\mathrm{CoB} 10$ & $\mathrm{CoB} 15$ & $\mathrm{CoB} 20$ & Tod & CoT5 & CoT10 & CoT15 & CoT20 \\
\hline \multirow[t]{3}{*}{$\mathrm{Mn}-\mathrm{O}_{1 \mathrm{st}}$} & $\mathrm{CN}$ & $5.36(89)$ & $5.04(59)$ & $4.30(51)$ & $5.35(64)$ & $5.15(62)$ & $5.46(66)$ & $5.57(69)$ & $4.97(51)$ & $5.51(1.05)$ & $5.44(72)$ \\
\hline & $\mathrm{R}(\AA)$ & $1.907(7)$ & $1.908(5)$ & $1.909(5)$ & $1.904(5)$ & $1.906(5)$ & $1.901(6)$ & $1.901(5)$ & $1.903(4)$ & $1.904(8)$ & $1.903(5)$ \\
\hline & $\sigma^{2}\left(\AA^{2}\right)$ & $0.004(1)$ & $0.003(1)$ & $0.003(1)$ & $0.004(1)$ & $0.004(1)$ & $0.004(1)$ & $0.004(1)$ & $0.003(1)$ & $0.004(1)$ & $0.004(1)$ \\
\hline $\mathrm{Mn}-\mathrm{O}_{2 \mathrm{nd}}$ & $\mathrm{R}(\AA)^{\mathrm{a})}$ & $3.610(81)$ & $3.656(31)$ & $3.641(33)$ & $3.644(31)$ & $3.635(30)$ & $3.582(57)$ & $3.601(40)$ & $3.625(29)$ & $3.636(78)$ & $3.623(34)$ \\
\hline \multirow[t]{3}{*}{$\mathrm{Mn}-\mathrm{Me}_{\mathrm{E}}$} & $\mathrm{CN}$ & $5.91(1.54)$ & $6.19(75)$ & $5.00(67)$ & $6.12(68)$ & $5.58(68)$ & 4.63(90) & $5.22(76)$ & $4.99(59)$ & $5.49(93)$ & $5.53(75)$ \\
\hline & $\mathrm{R}(\AA)$ & $2.901(10)$ & $2.895(6)$ & $2.884(6)$ & $2.874(6)$ & $2.871(7)$ & $2.883(7)$ & $2.874(6)$ & $2.874(6)$ & $2.866(8)$ & $2.864(6)$ \\
\hline & $\sigma^{2}\left(\AA^{2}\right)$ & $0.008(2)$ & $0.007(1)$ & $0.005(1)$ & $0.006(1)$ & $0.005(1)$ & $0.006(1)$ & $0.006(1)$ & $0.006(1)$ & $0.005(1)$ & $0.005(1)$ \\
\hline \multirow[t]{2}{*}{$\mathrm{Mn}-\mathrm{Me}_{\mathrm{C}}$} & $\mathrm{CN}$ & $2.61(1.32)$ & $2.76(71)$ & $2.14(55)$ & $2.69(65)$ & $2.52(54)$ & $2.60(83)$ & $2.97(70)$ & $2.75(58)$ & $2.99(88)$ & $2.86(76)$ \\
\hline & $\mathrm{R}(\AA)$ & $3.466(72)$ & $3.512(23)$ & $3.501(24)$ & $3.500(20)$ & $3.496(18)$ & $3.450(38)$ & $3.463(23)$ & $3.483(18)$ & $3.485(37)$ & $3.477(18)$ \\
\hline $\mathrm{CN}_{\mathrm{C}} / \mathrm{CN}_{\mathrm{E}}$ & & 0.44 & 0.45 & 0.43 & 0.44 & 0.45 & 0.56 & 0.57 & 0.55 & 0.54 & 0.52 \\
\hline$\delta \mathrm{E}_{0}(\mathrm{eV})$ & & $-7.12(1.63)$ & $-6.56(1.04)$ & $-5.49(98)$ & $-8.17(1.12)$ & $-7.38(98)$ & $-7.15(1.33)$ & $-8.12(1.07)$ & $-5.35(95)$ & $-7.98(1.66)$ & $-8.14(1.05)$ \\
\hline $\mathrm{R}$ factor $(\%)$ & & 0.04 & 0.01 & 0.01 & 0.01 & 0.01 & 0.02 & 0.02 & 0.01 & 0.01 & 0.01 \\
\hline
\end{tabular}

Coordination numbers $(\mathrm{CN})$ and Debye-Waller factors $\left(\sigma^{2}\right)$ of $\mathrm{Mn}-\mathrm{O}$ shells were refined together, as were Debye-Waller factors of the two Mn-Me shells. 
Table 6

Best fits via linear combination fitting of Mn K-edge $\chi(\mathrm{k})$ for reflux products

\begin{tabular}{ccc}
\hline Sample & Best Fitting & Error \\
\hline CoT10 & 0.33 CoT5 + 0.67 CoB10 & 0.09 \\
CoT15 & 0.23 CoT5 + 0.77 CoB15 & 0.07 \\
CoT20 & 0.21 CoT5 + 0.79 CoB20 & 0.04 \\
\hline
\end{tabular}


Table 7

Structural parameters derived from Co K-edge EXAFS fitting over 1-4

\begin{tabular}{llllllllll}
\hline Atomic pairs & & CoB5 & CoB10 & CoB15 & CoB20 & CoT5 & CoT10 & CoT15 & CoT20 \\
Co-O1st & $\mathrm{CN}$ & $6.62(1.58)$ & $4.66(66)$ & $5.75(88)$ & $4.61(51)$ & $7.21(2.62)$ & $5.21(66)$ & $4.91(59)$ & $4.77(69)$ \\
& $\mathrm{R}(\AA)$ & $1.909(9)$ & $1.913(5)$ & $1.909(8)$ & $1.915(5)$ & $1.907(17)$ & $1.913(6)$ & $1.913(5)$ & $1.914(7)$ \\
& $\sigma^{2}\left(\AA^{2}\right)$ & $0.001(1)$ & $0.001(1)$ & $0.004(1)$ & $0.002(1)$ & $0.004(2)$ & $0.002(1)$ & $0.002(1)$ & $0.002(1)$ \\
Co-O2nd & $\mathrm{R}(\AA) \mathrm{a})$ & $3.713(52)$ & $3.460(46)$ & $3.660(29)$ & $3.495(35)$ & $3.666(34)$ & $3.469(45)$ & $3.486(37)$ & $3.481(44)$ \\
$\mathrm{Co}-\mathrm{MeE}$ & $\mathrm{CN}$ & $6 * \mathrm{f}$ & $6 * \mathrm{f}$ & $6 * \mathrm{f}$ & $6 * \mathrm{f}$ & $6 * \mathrm{f}$ & $6 * \mathrm{f}$ & $6 * \mathrm{f}$ & $6 * \mathrm{f}$ \\
& $\mathrm{R}(\AA)$ & $2.836(14)$ & $2.849(5)$ & $2.843(6)$ & $2.851(5)$ & $2.840(13)$ & $2.850(5)$ & $2.848(5)$ & $2.846(6)$ \\
& $\sigma^{2}\left(\AA^{2}\right)$ & $0.002(1)$ & $0.003(1)$ & $0.002(0.5)$ & $0.003(0.5)$ & $0.002(1)$ & $0.003(1)$ & $0.003(1)$ & $0.003(1)$ \\
$\mathrm{Co}-\mathrm{MeC}$ & $\mathrm{CN}$ & $6 *(1-\mathrm{f})$ & $6 *(1-\mathrm{f})$ & $6 *(1-\mathrm{f})$ & $6 *(1-\mathrm{f})$ & $6 *(1-\mathrm{f})$ & $6 *(1-\mathrm{f})$ & $6 *(1-\mathrm{f})$ & $6 *(1-\mathrm{f})$ \\
& $\mathrm{R}(\AA)$ & $3.528(68)$ & $3.364(57)$ & $3.474(16)$ & $3.401(35)$ & $3.475(34)$ & $3.469(37)$ & $3.395(29)$ & $3.404(30)$ \\
$\mathrm{f}$ & & $0.84(13)$ & $0.86(9)$ & $0.75(5)$ & $0.77(6)$ & $0.73(14)$ & $0.83(10)$ & $0.79(7)$ & $0.81(10)$ \\
$\delta \mathrm{E} 0(\mathrm{eV})$ & & $-3.75(2.50)$ & $-0.81(91)$ & $-2.09(1.32)$ & $-0.37(94)$ & $-3.13(2.62)$ & $0.12(1.03)$ & $-0.51(99)$ & $-0.05(1.07)$ \\
$\mathrm{R}$ factor $(\%)$ & & 0.04 & 0.003 & 0.006 & 0.003 & 0.05 & 0.005 & 0.004 & 0.006 \\
\hline
\end{tabular}

Coordination numbers $(\mathrm{CN})$ and Debye-Waller factors $\left(\sigma^{2}\right)$ of Co-O shells were refined together, as were Debye-Waller factors of the two Co-Me shells.

Parameter $f$ represents the proportion of $\mathrm{Co}$ in an edge-sharing configuration in each of the $\mathrm{CoB}$ and $\mathrm{CoT}$ sample. 
(a)

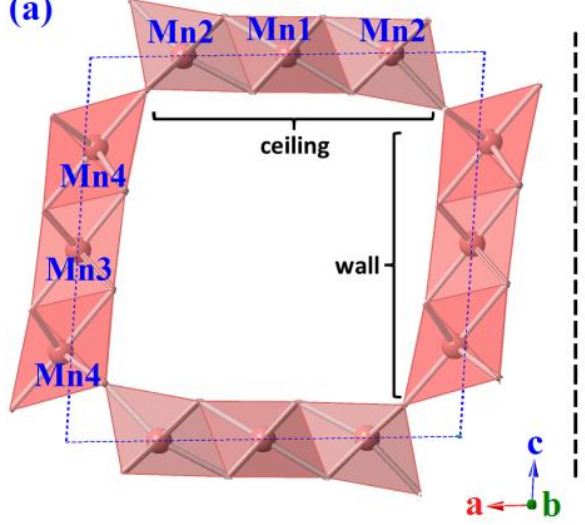

(b)

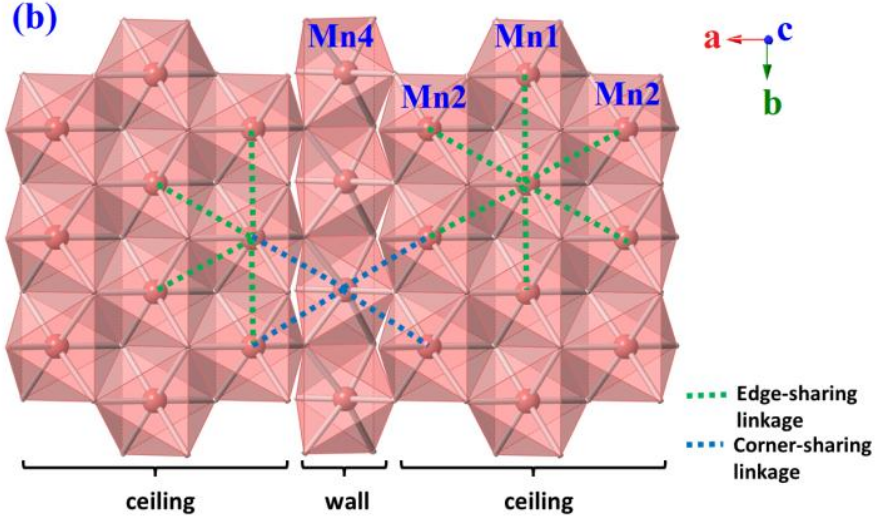

2 Fig. 1 Crystal structure of todorokite with a $3 \times 3$ tunnel size observed along $\boldsymbol{b}^{*}$ (a) and $\boldsymbol{c}^{*}$ (b)

3 direction

4

5 


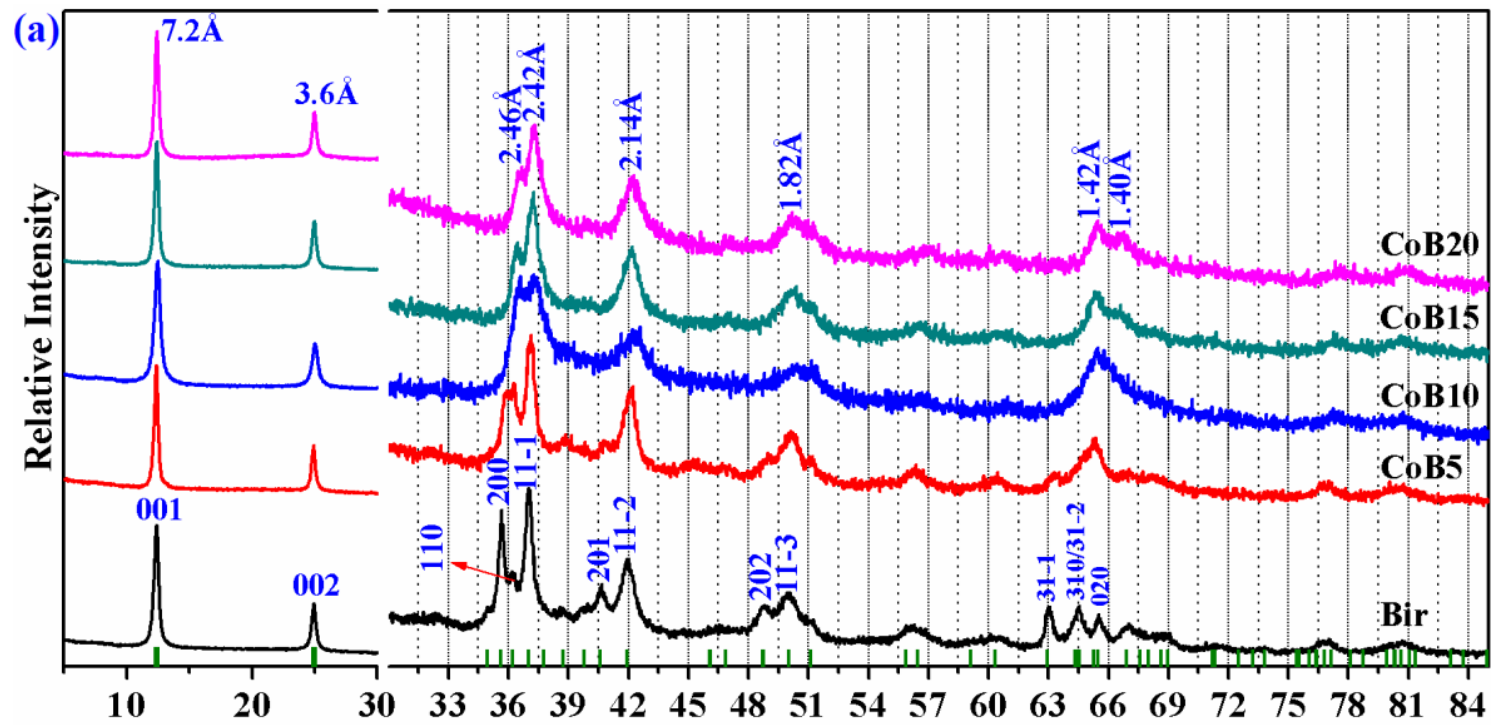

(b) 2 theta(degree, $\mathrm{Cu} \mathrm{K \alpha}$ )

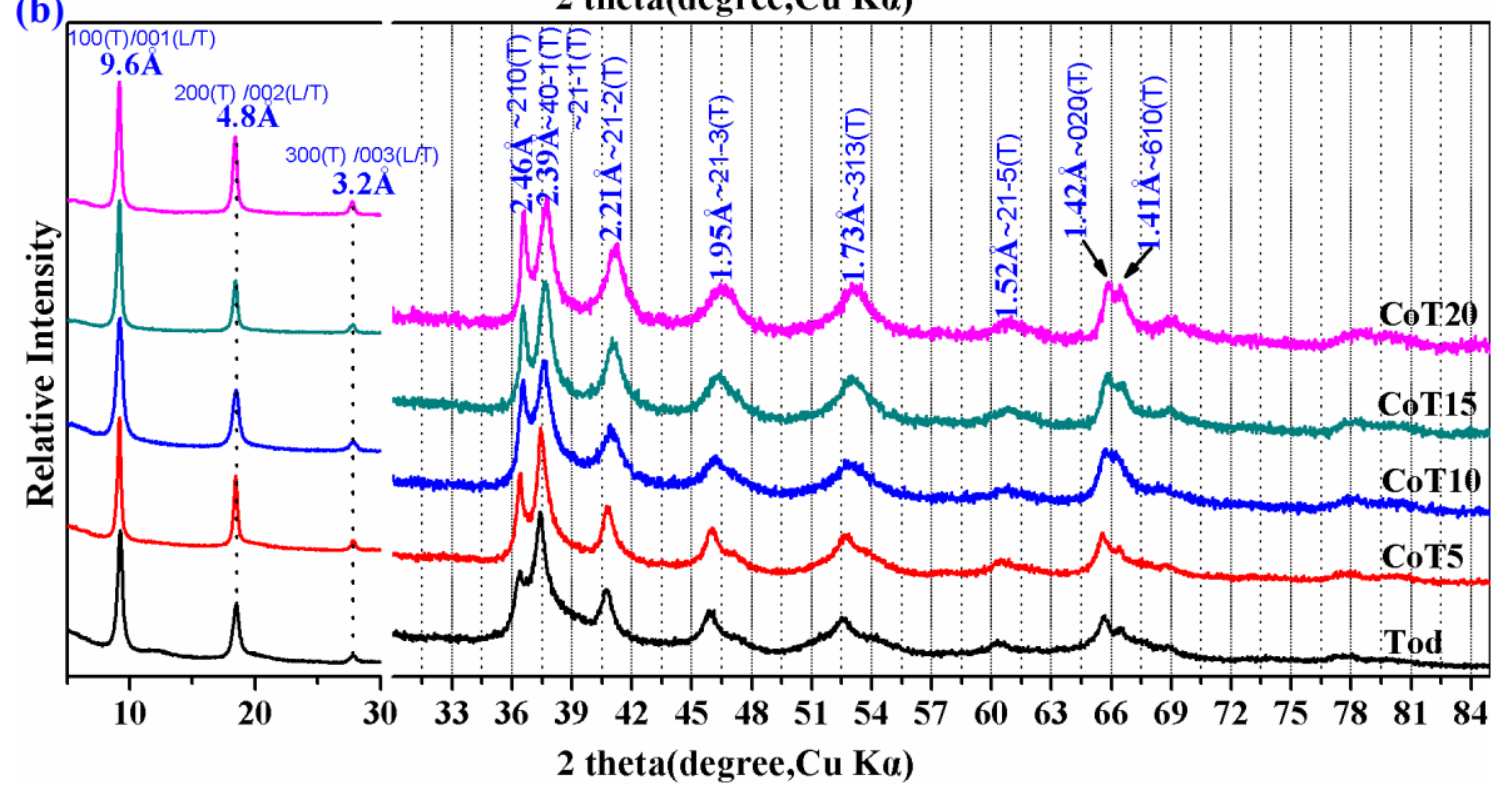

Fig. 2. Powder XRD patterns of layered precursors (a) and reflux products (b). Diffracted intensities peaks are normalized in the low and high angle region. Green ticks at the bottom of (a) indicate

9 reflections of triclinic birnessite (JCPDS 43-1456). In (b), (L) and (T) indicate reflections of $9.6 \AA$ layered Mn oxide and of todorokite (JCPDS 38-475), respectively. 

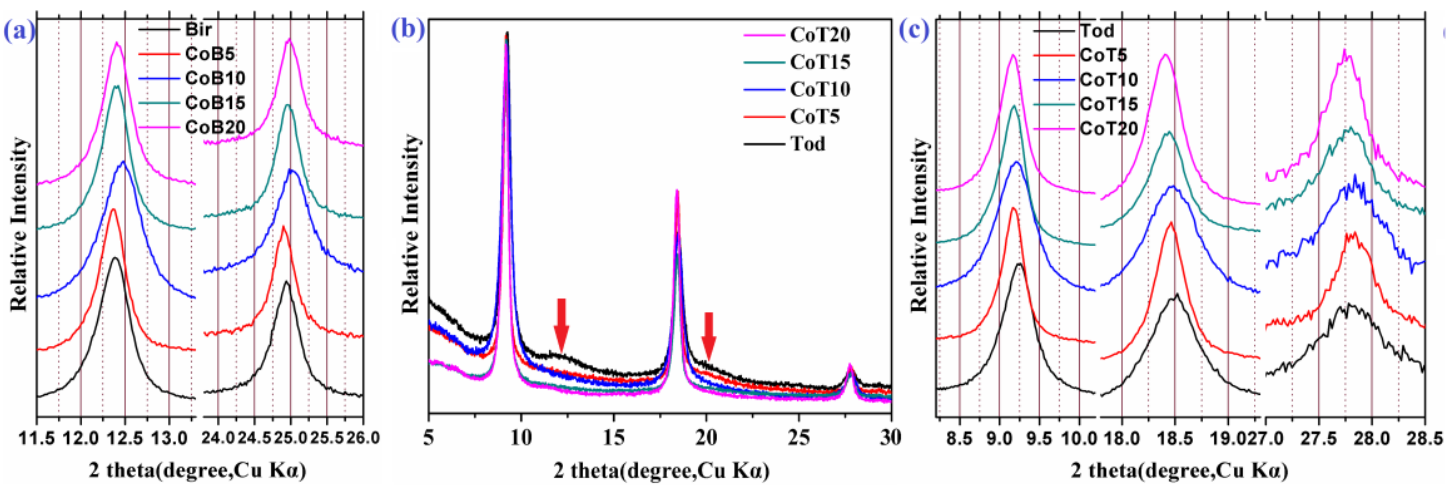

Fig. 3. Powder XRD patterns in the low angle region of the layered precursors (a), and the reflux products (b) and (c). Arrows in (b) indicate the broad hump and shoulder in the patterns.

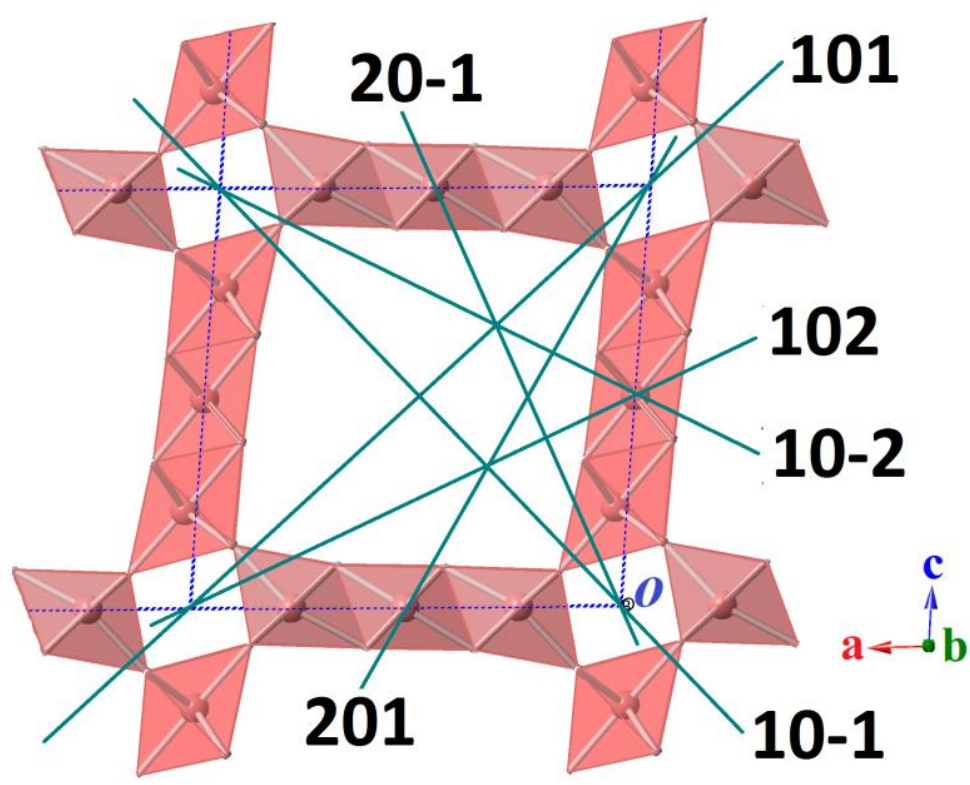

18 Fig. 4. Lattice planes of todorokite with a uniform $3 \times 3$ tunnel structure 


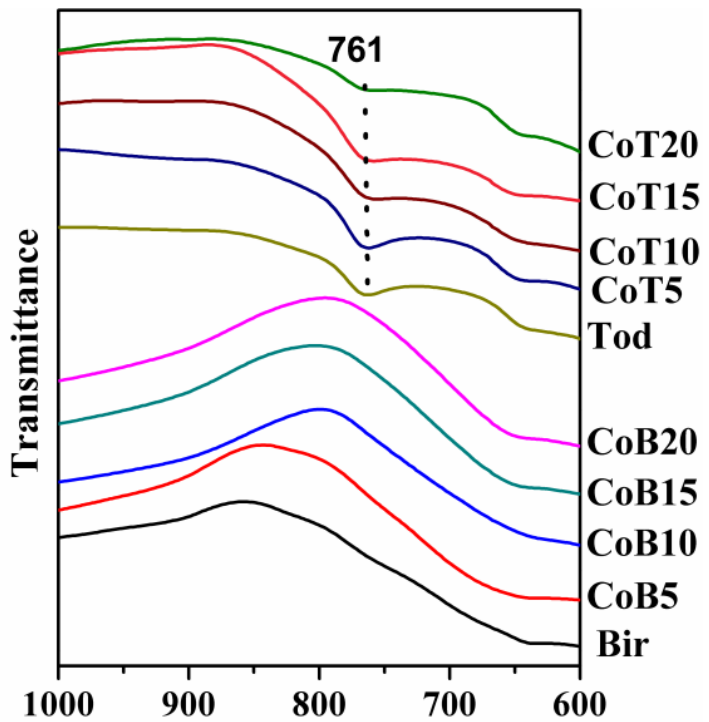

21 Fig. 5. FTIR spectra of layered precursors (bottom) and reflux products (top) 

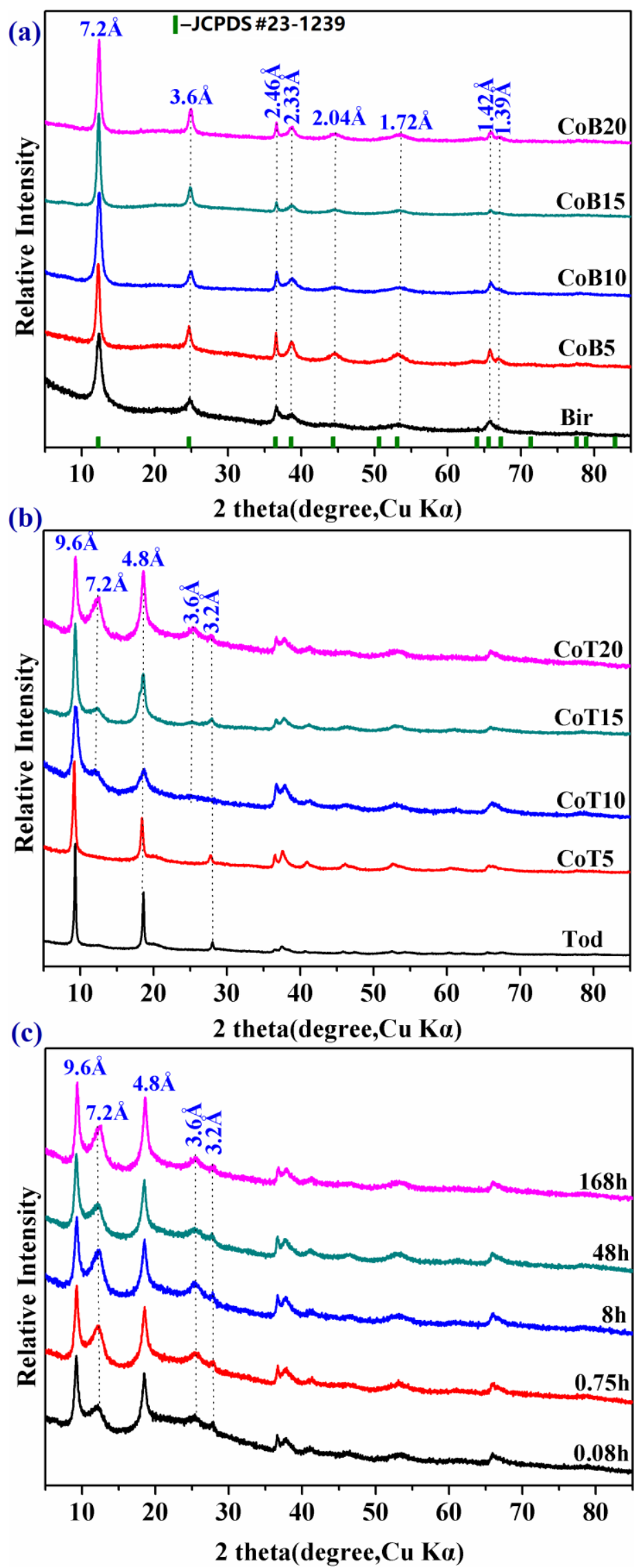

Fig. 6. XRD patterns of layered precursors and reflux products after nitric acid treatment: (a) layered precursors; (b) reflux products; (c) sample CoT20 after different nitric acid treatment durations. 

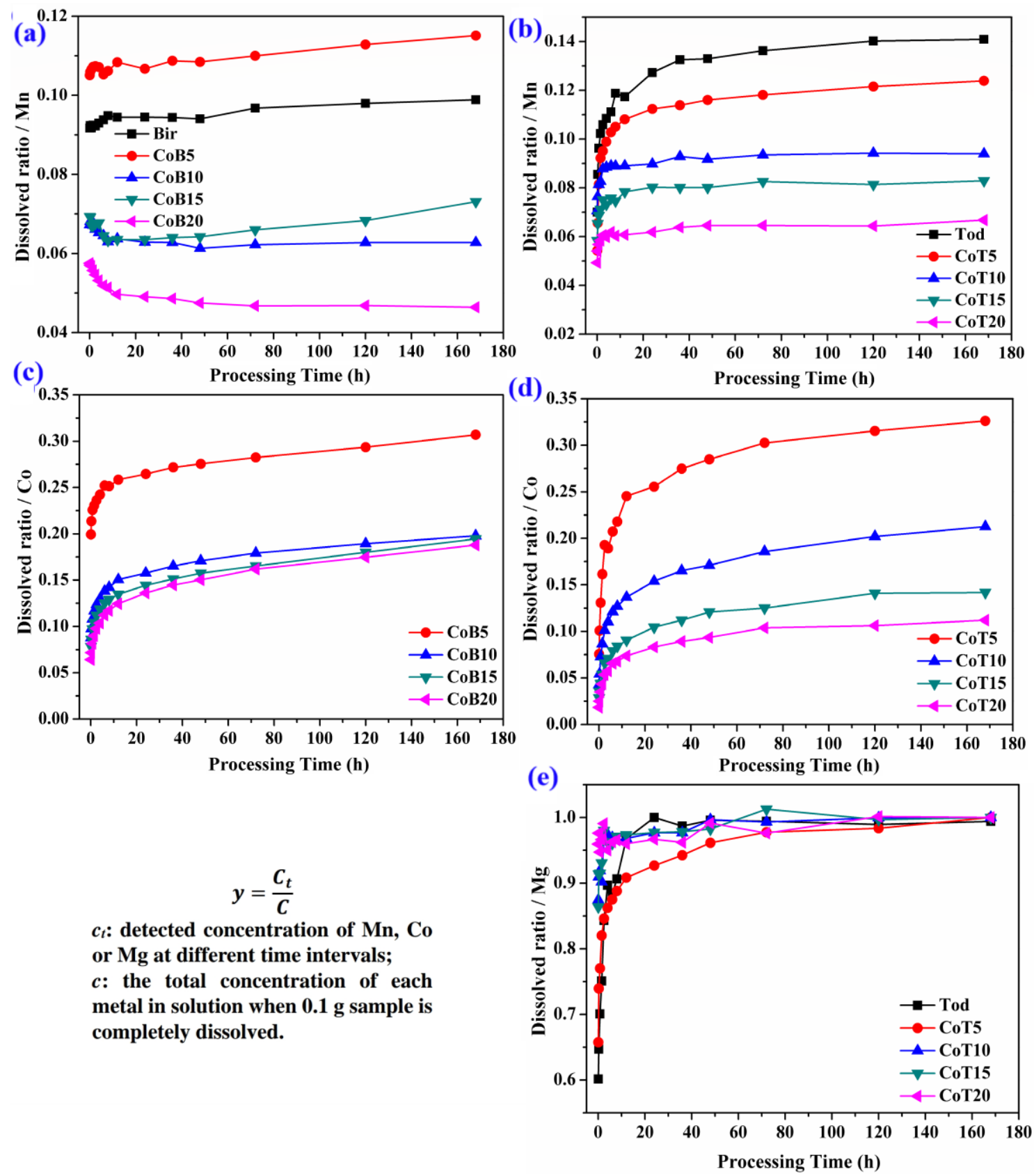

$$
y=\frac{C_{t}}{C}
$$

$c_{t}$ : detected concentration of $\mathrm{Mn}, \mathrm{Co}$ or Mg at different time intervals; $c$ : the total concentration of each metal in solution when $0.1 \mathrm{~g}$ sample is completely dissolved.

Fig. 7. Ratios of element ( $\mathrm{Mn}, \mathrm{Co}, \mathrm{Mg}$ ) released during nitric acid treatment. $\mathrm{Mn}$ for $\mathrm{CoB}$ (a) and $\mathrm{CoT}$ (b). Co for $\mathrm{CoB}$ (c) and $\mathrm{CoT}(\mathrm{d}) . \mathrm{Mg}$ for $\mathrm{CoT}$ (e). 

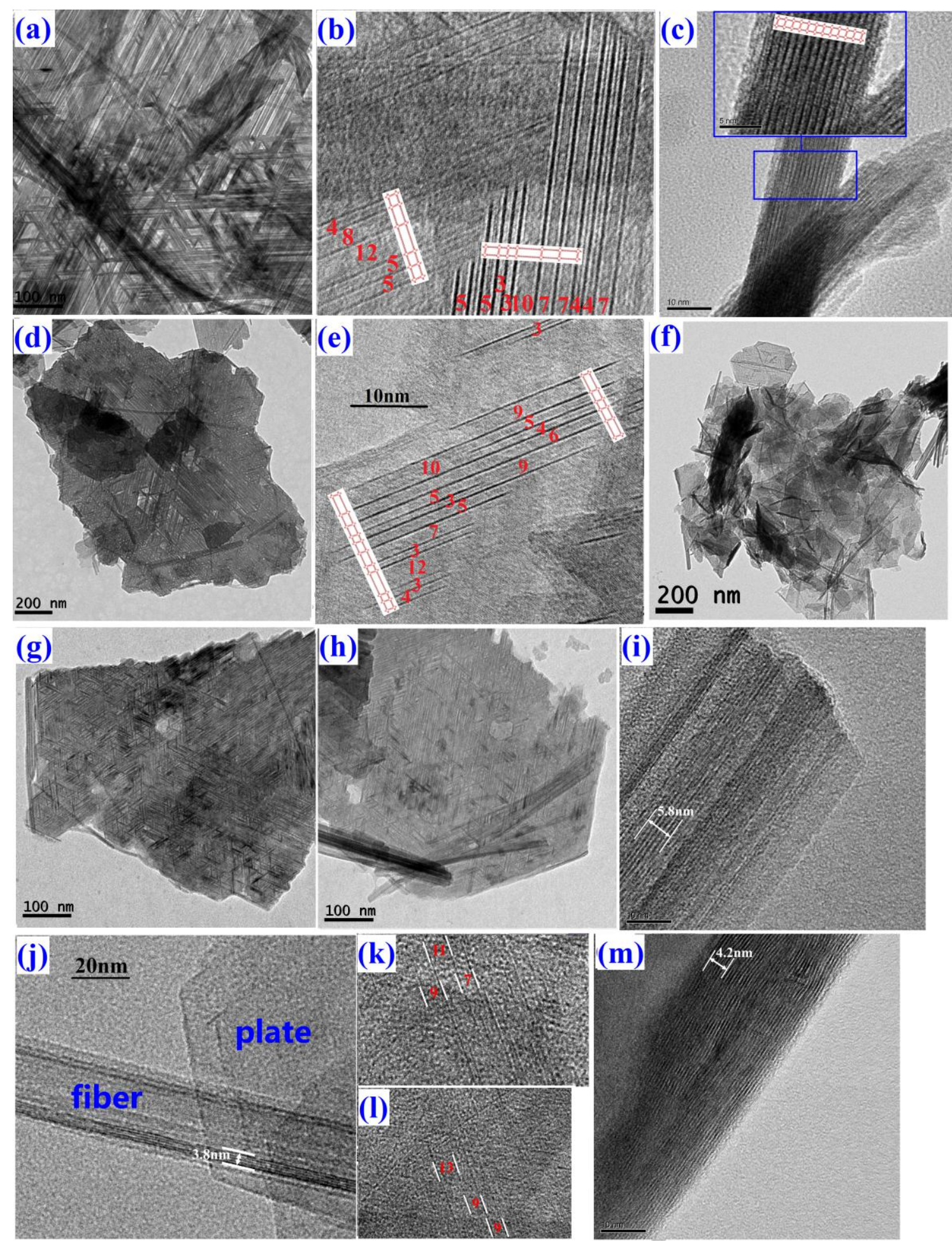

Fig. 8. High resolution transmission electron microscopy images: Tod: (a-c); CoT5: (d and e); CoT10: (f); CoT15: (g); CoT20: (h-m). Red numbers in the pictures indicate the number of $\mathrm{MnO}_{6}$ octahedra between lattice fringes, models schematize the structure of marked areas observed along the $\boldsymbol{b}^{*}$ direction. White labels in (i), (j) and (m) indicate the distance corresponding to 6, 4 and 6 lattice fringes, respectively. 

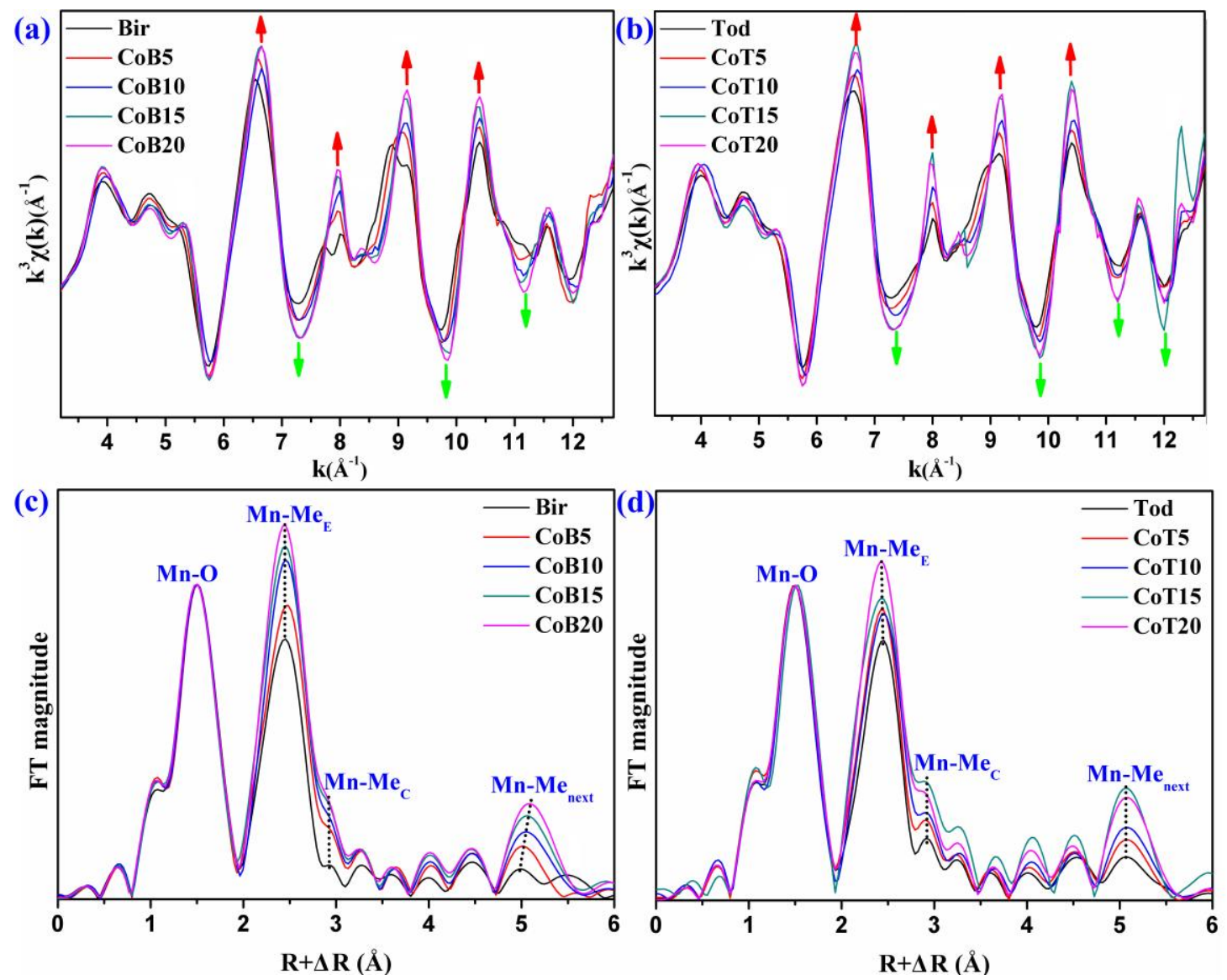

Fig. 9. Mn K-edge EXAFS spectra (a and b) and their respective Fourier transforms ( $c$ and d) for layered precursors and reflux products. Arrows in (a) and (b) highlight modifications of signal amplitude (see text for details). Intensity of the Fourier transforms are normalized to the first Mn-O shell (c and d). 


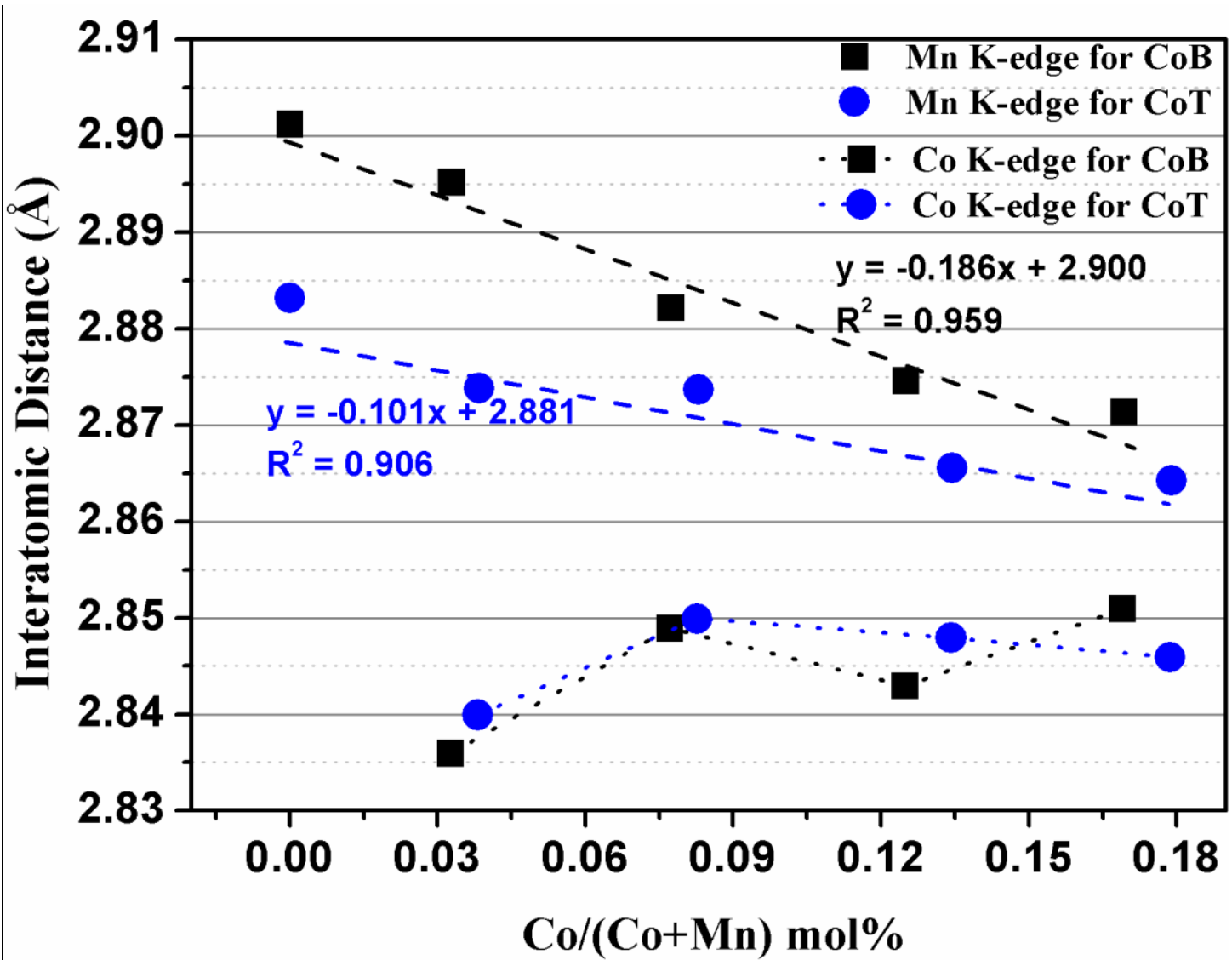

Fig. 10. Evolution of interatomic $\mathrm{Mn} / \mathrm{Co}-\mathrm{Me}_{\mathrm{E}}$ distances in layered precursors and reflux products as a function of their Co content. 

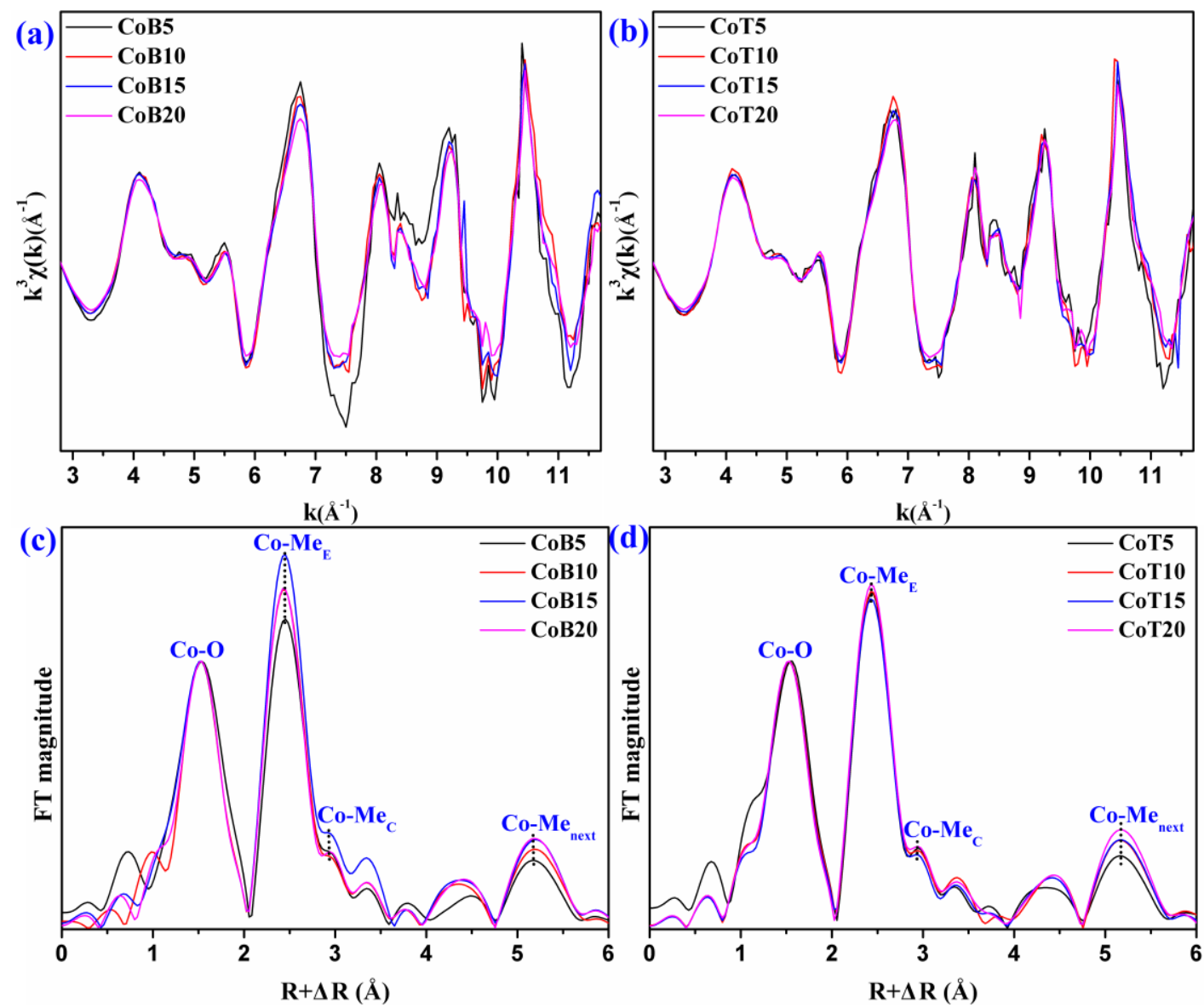

Fig. 11. Co K-edge EXAFS spectra ( $a$ and $b$ ) and their respective Fourier transforms ( $c$ and d) for layered precursors and reflux products. Intensity of the Fourier transforms are normalized to the first Mn-O shell (c and d). 


\section{Supplementary information to:}

\section{Transformation of Co-containing birnessite to todorokite: Effects of Co on the transformation and implications for Co mobility}

Zhongkuan $\mathrm{Wu}^{\mathrm{a}}$, Caroline L. Peacock ${ }^{\mathrm{b}}$, Bruno Lanson ${ }^{\mathrm{c}}$, Hui Yin ${ }^{\mathrm{a}}$, Lirong Zheng ${ }^{\mathrm{d}}$, Zhongjun Chen ${ }^{\mathrm{d}}$, Wenfeng Tan ${ }^{\mathrm{a}}$, Guohong Qiu ${ }^{\mathrm{a}}$, Fan Liu ${ }^{\mathrm{a}, *}$, Xionghan Feng ${ }^{\mathrm{a}, *}$

${ }^{\mathrm{a}}$ Key Laboratory of Arable Land Conservation (Middle and Lower Reaches of Yangtse River) Ministry of Agriculture, College of Resources and Environment, Huazhong Agricultural University, Wuhan 430070, China.

${ }^{\mathrm{b}}$ School of Earth and Environment, University of Leeds, Leeds LS2 9JT, UK.

${ }^{\mathrm{c}}$ University of Grenoble Alpes, CNRS, ISTerre, F-38000 Grenoble, France.

${ }^{\mathrm{d}}$ Beijing Synchrotron Radiation Facility, Institute of High Energy Physics, Chinese Academy of Sciences, Beijing 100039, China.

${ }^{*}$ Corresponding author:

Tel: +862787280271

E-mail: liufan@mail.hzau.edu.cn (F. Liu), fxh73@mail.hzau.edu.cn (X. Feng). 


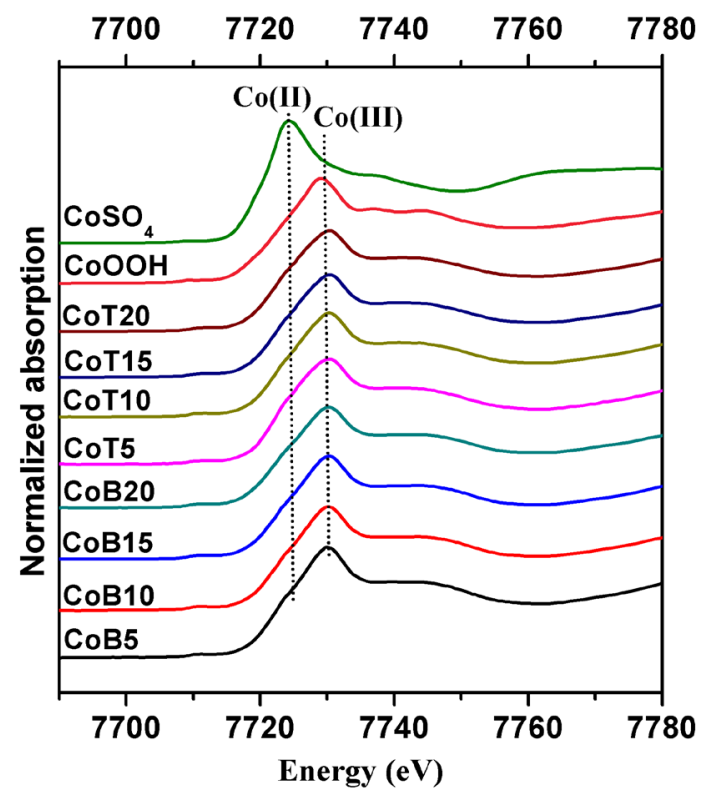

Fig. S1. Co K-edges XANES spectra of $\mathrm{Co}$ in $\mathrm{CoB}, \mathrm{CoT}$ and two standard samples of $\mathrm{Co}$ (II) $\left(\mathrm{CoSO}_{4}\right)$ and $\mathrm{Co}(\mathrm{III})(\mathrm{CoOOH})$, indicating that the oxidation state of $\mathrm{Co}$ in $\mathrm{CoB}$ and $\mathrm{CoT}$ is $\mathrm{Co}(\mathrm{III})$.

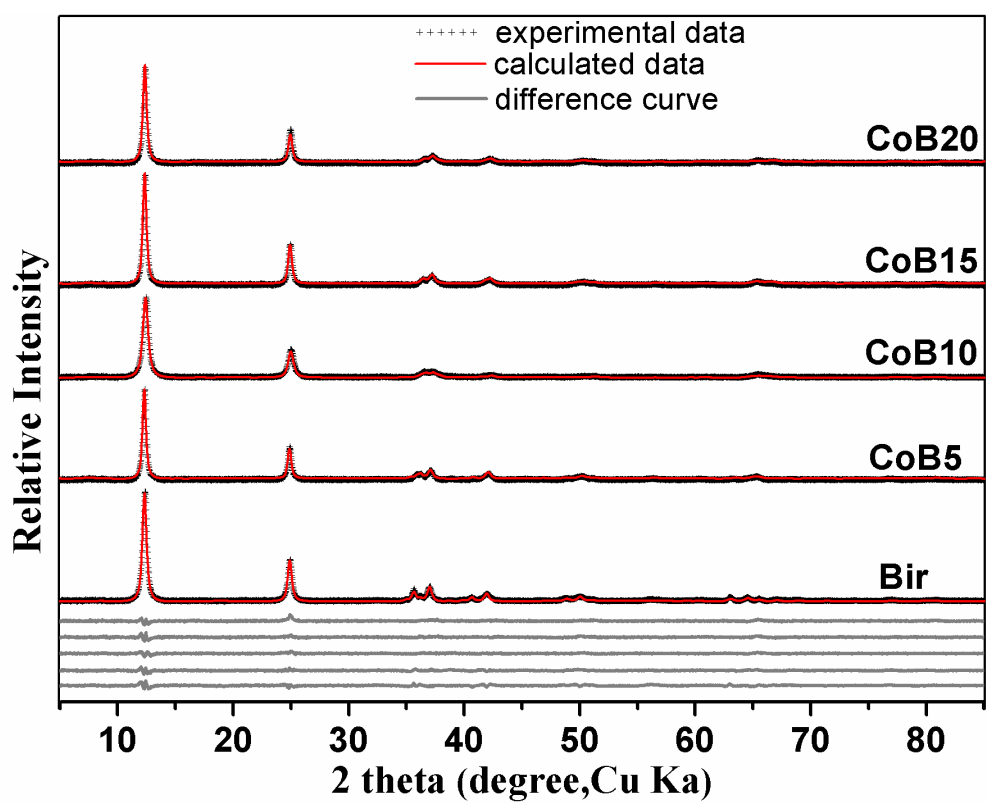

Fig. S2. Rietveld refinement of layered precursors. The gray lines at the bottom of the figure are difference curves for Bir, CoB5, CoB10, CoB15 and CoB20 from bottom to top. 

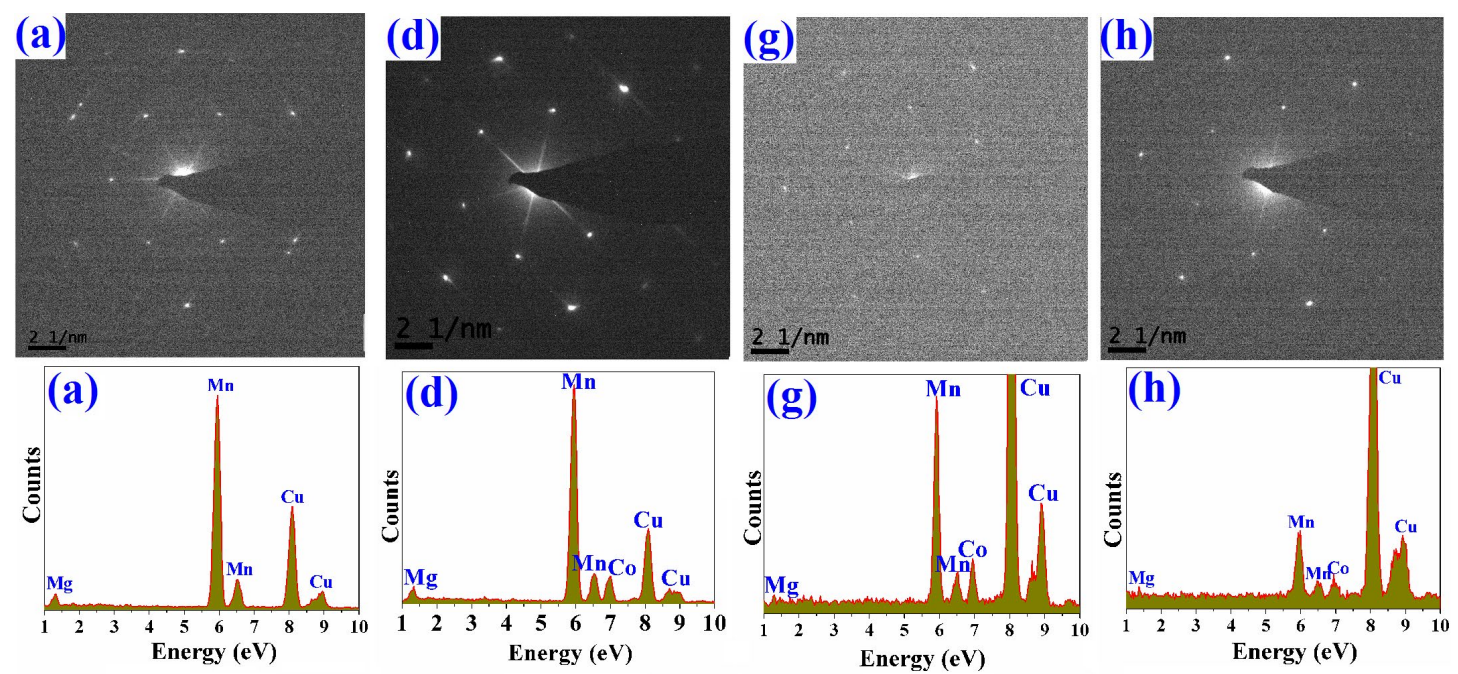

Fig. S3. Electron diffraction patterns (top) and energy-dispersive X-ray spectra (bottom) of reflux products: (a) Tod; (d) CoT5; (g) CoT15; (h) CoT20. Labels refer to individual particles shown on corresponding Fig. 8.

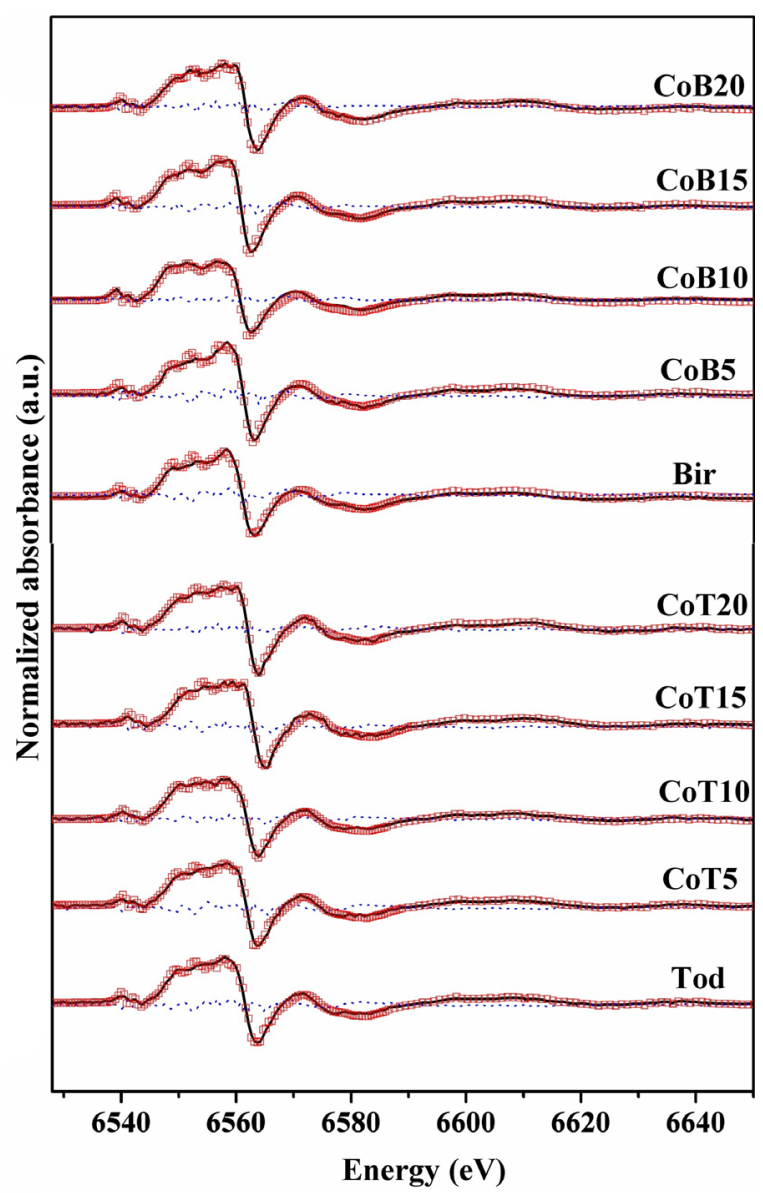

Fig. S4. Fit of the Mn K-edge XANES $1^{\text {st }}$ derivative using the Combo method (Manceau et al.,2012). Squares, solid lines and dotted lines represent experimental data, best fits and residual. The references used to fit the data are those used by Manceau et al. (2012). 

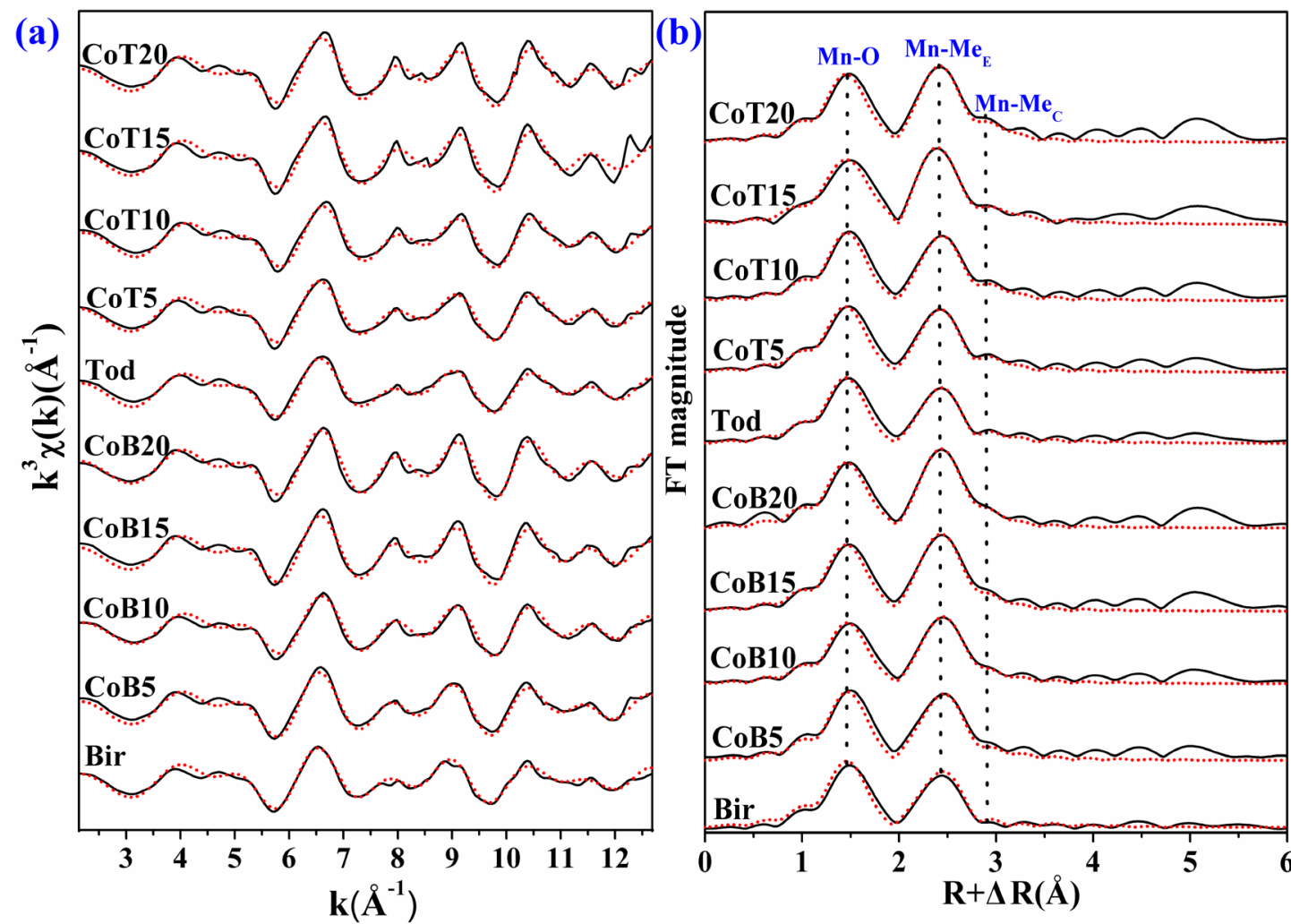

Fig. S5. Mn K-edge EXAFS spectra (a) and their Fourier transforms (b) for layered precursors and reflux products (solid black lines) with their best simulations overlaid (dotted red lines).

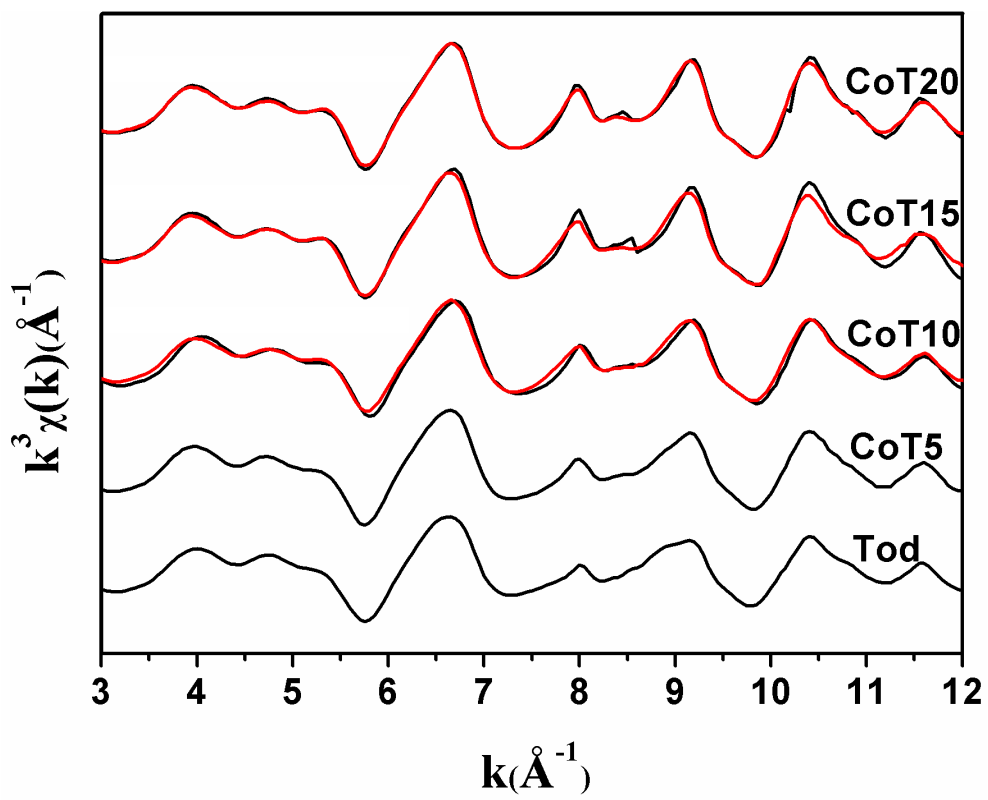

Fig. S6. Linear combination fits of Mn K-edge $\chi(\mathrm{k})$ EXAFS spectra for reflux products. Black and red solid lines are data and best fits, respectively. CoT5 and corresponding CoB spectra were used as reference compounds to determine the proportion of layered vs. tunnel and layered Mn oxides in the reflux products. 

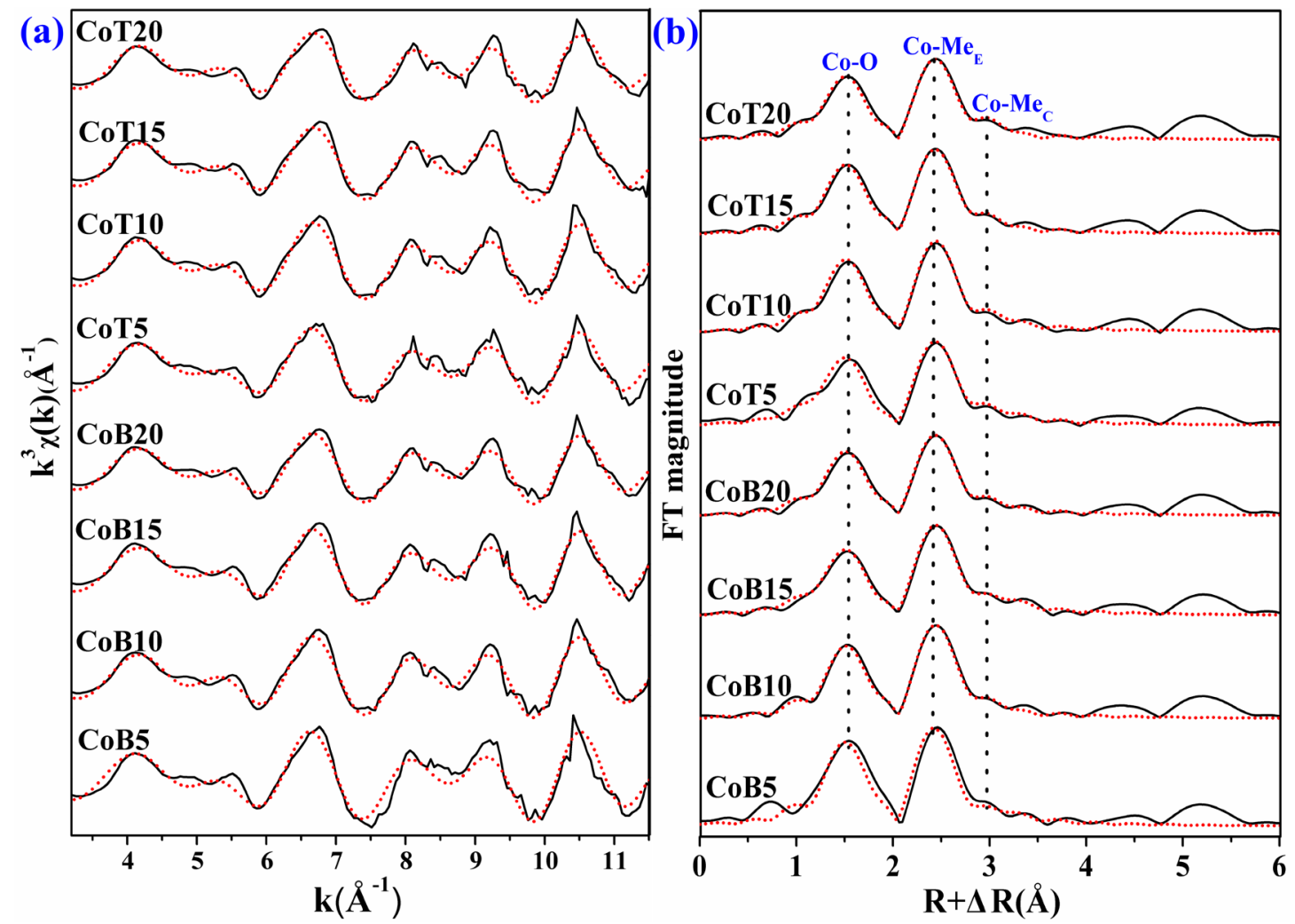

Fig. S7 Co K-edge EXAFS spectra (a) and their Fourier transforms (b) for layered precursors and reflux products (solid black lines) with their best simulations overlaid (dotted red lines). 
Table S1.

Relative contributions of reference spectra to the best fits of Mn K-edge XANES first derivatives for layered precursors and reflux products shown in Fig. S4.

\begin{tabular}{cccccccccccccccccccc}
\hline Samples & $2-1$ & $2-2$ & $2-3$ & $2-4$ & $2-5$ & $2-6$ & $2-7$ & $2-8$ & $3-1$ & $3-2$ & $3-3$ & $3-4$ & $3-5$ & $4-1$ & $4-2$ & $4-3$ & $4-4$ & Total \\
\hline Bir & n.d. & n.d. & 0.7 & n.d. & 1.6 & n.d. & n.d. & n.d. & n.d. & 24.1 & n.d. & n.d. & n.d. & 14.3 & n.d. & n.d. & 51.9 & 92.6 \\
CoB5 & n.d. & n.d. & 2.0 & n.d. & 0.5 & n.d. & n.d. & n.d. & n.d. & 15.5 & n.d. & n.d. & n.d. & 5.6 & 7.6 & n.d. & 62.4 & 93.5 \\
CoB10 & n.d. & n.d. & n.d. & n.d. & 3.5 & n.d. & 0.4 & n.d. & n.d. & 23.7 & n.d. & n.d. & 0.3 & 1.4 & 13.6 & n.d. & 46.5 & 89.4 \\
CoB15 & n.d. & n.d. & 2.5 & n.d. & 2.4 & n.d. & n.d. & n.d. & n.d. & 6.1 & n.d. & n.d. & n.d. & n.d. & 12.7 & n.d. & 68.9 & 92.5 \\
CoB20 & n.d. & n.d. & 1.4 & n.d. & 3.3 & n.d. & n.d. & n.d. & 1.1 & 7.7 & n.d. & n.d. & n.d. & n.d. & 16.0 & 5.1 & 58.3 & 92.8 \\
Tod & n.d. & n.d. & n.d. & n.d. & 1.5 & n.d. & n.d. & n.d. & n.d. & 23.4 & n.d. & n.d. & n.d. & 3.3 & 11.8 & 5.0 & 50.5 & 95.6 \\
CoT5 & n.d. & n.d. & n.d. & n.d. & 1.8 & n.d. & n.d. & n.d. & n.d. & 20.9 & n.d. & n.d. & n.d. & n.d. & 13.7 & n.d. & 54.8 & 91.1 \\
CoT10 & n.d. & n.d. & n.d. & n.d. & 4.0 & n.d. & n.d. & n.d. & n.d. & 24.1 & n.d. & n.d. & n.d. & 2.7 & 10.5 & 6.0 & 45.6 & 92.9 \\
CoT15 & n.d. & n.d. & 1.4 & n.d. & n.d. & n.d. & n.d. & n.d. & 11.2 & n.d. & 3.1 & 1.0 & n.d. & n.d. & 15.4 & 9.7 & 52.3 & 94.1 \\
CoT20 & n.d. & n.d. & 1.7 & n.d. & 2.9 & n.d. & n.d. & n.d. & 6.7 & 0.5 & n.d. & n.d. & n.d. & n.d. & 14.8 & 11.6 & 56.2 & 94.5 \\
\hline
\end{tabular}

The reference numbers are those of Manceau et al.(2012). n.d.: not detected 